Review Article

\title{
Differentiated Evaluation of Extract-Specific Evidence on Cimicifuga racemosa's Efficacy and Safety for Climacteric Complaints
}

\author{
A.-M. Beer ${ }^{1}$ and A. Neff ${ }^{2}$ \\ ${ }^{1}$ Department of Naturopathy, Blankenstein Hospital, Im Vogelsang 5-11, 45527 Hattingen, Germany \\ ${ }^{2}$ Department of Gynecology, Lübbecke Hospital, Virchowstraße 65, 32312 Lübbecke, Germany
}

Correspondence should be addressed to A.-M. Beer; andre.beer@klinik-blankenstein.de

Received 13 May 2013; Accepted 21 June 2013

Academic Editor: Brent Bauer

Copyright (C) 2013 A.-M. Beer and A. Neff. This is an open access article distributed under the Creative Commons Attribution License, which permits unrestricted use, distribution, and reproduction in any medium, provided the original work is properly cited.

\begin{abstract}
Past reviews on Cimicifuga racemosa (CR) without differentiation between extracts, quality, and indication altogether led to inconsistent data. Therefore, for the first time, we meet the requirements of the system's logic of evidence-based phytotherapy by taking into consideration extracts, pharmaceutical quality (reflected in a regulatory status as medicinal product), and indication. A literature search for clinical studies examining CR's efficacy and safety for menopausal complaints was conducted. The results were sorted by type of extract, regulatory status, and indication. Accordingly, Oxford Levels of Evidence (LOE) and Grades of Recommendation (GR) were determined. CR extracts demonstrated a good to very good safety in general, on estrogen-sensitive organs and the liver. However, only registered CR medicinal products were able to prove their efficacy. Best evidence was provided by the isopropanolic CR extract (iCR): the multitude of studies including more than 11,000 patients demonstrated consistent confirmatory evidence of LOE $1 \mathrm{~b}$ (LOE la for safety) leading to GR A. The studies on the ethanolic extract BNO 1055 including more than 500 patients showed exploratory evidence of LOE $2 \mathrm{~b}$ resulting in GR B. A positive benefit-risk profile is stated and limited to Cimicifuga racemosa products holding a marketing authorisation for treating climacteric complaints.
\end{abstract}

\section{Introduction}

Frequently climacteric complaints, especially vasomotor symptoms (hot flashes, sweatings) and vaginal dryness, are treated with hormone therapy (HT) $[1,2]$. Comprehensive clinical studies in the 1990s (Women's Health Initiative Study (WHI) and Women's International Study of long Duration Oestrogen after Menopause (WISDOM)) have demonstrated, however, that women who were treated with hormone therapy for climacteric complaints for several years had a significantly increased risk of breast cancer, cardiovascular events, pulmonary embolism, and dementia compared to placebo [3-5]. Both patients as well as physicians have been looking for effective and safe alternatives [3,6]. Different extracts from Cimicifuga racemosa (Black Cohosh, Traubensilberkerze) are clinically used for climacteric complaints [7]. The monograph for Cimicifuga racemosa by the Herbal Medicinal Product Committee (HMPC) of the European Medicines Agency (EMA) stipulates a clear therapeutic benefit for three specific extracts and confirms a positive benefit-risk profile [8]. The extract production with a proven pharmaceutical quality under GMP conditions is the prerequisite.

The rhizome of Cimicifuga racemosa with attached roots is harvested in fall after the fruit has ripened and is used fresh or in dried form. The rhizome of Cimicifuga racemosa contains cycloartenol-type triterpene glycosides (amongst others actein, cimicifugoside, cimiracemoside A, and 23-epi-26-deoxyactein) and phenylpropanoids such as hydroxycinnamic acids. Further ingredients include alkaloids, N-methylserotonin, starch, fatty acids, resin, and tannins [9]. The isoflavone formononetin, once described as an ingredient, could not be detected uniformly in newer studies of extracts of Cimicifuga racemosa [10, 11]. 
The evidence regarding the aggregate of the different types of Cimicifuga racemosa extracts available on the market has been evaluated rather differently by various reviews. In this context, the heterogeneity of the data [12], contradicting results [13] or the inconsistency of data [14] have been criticised. Problems arise from the fact that previous reviews included all types of Cimicifuga preparations, whether approved as medicinal products or other products (food supplements or individualized single preparations) and their use for most different indications, without any differentiation.

However, none of these reviews took into consideration the logical system of phytotherapy, which requires a differentiation by type of extract, pharmaceutical quality, and indication. Herbal extracts are multiple-substance mixtures with varying composition, depending on the extractant used and further distinctions specific for manufacture, harvest, or cultivation. This can lead to different efficacies [15].

In contrast to food supplements or dietary foods, state-ofthe-art proof of quality, efficacy, and safety is mandatory for the registration of herbal medicinal products. Strict quality criteria are applied especially for herbal medicinal products in all areas starting with drug harvesting followed by production of extract and finished product to the point of stability testing [16]. Quality and quality control are essential factors, which guarantee a stable efficacy and safety. The standardization of the manufacturing processes and a multitude of quality control steps from seed to finished product are prerequisites for the reproducibility of efficacy and safety demonstrated in studies and warrant a consistently high and certified quality of the medicinal product to both therapist and user.

Consequently, a differentiated review, evaluated by type of extract, pharmaceutical quality, and indication, which meets the characteristics and corresponds to the logical system of phytotherapy, is imperative. This review, therefore, differentiates clearly between registered and standardized medicinal products, on the one hand, and not registered/unspecified products, on the other. By means of a systematic review and assessment of the available evidence [17], it differentiates and evaluates the efficacy and the safety of phytopharmaceuticals from Cimicifuga racemosa for the treatment of climacteric complaints.

\section{Methodology}

2.1. Search Algorithm. We searched the databases MEDLINE, BIOSIS, EMBASE, EMBASE Alert, and PubMed for clinical studies with Cimicifuga racemosa. Furthermore, our research was complemented by a manual search in the library of authors. Goal of the literature search was the identification of clinical studies exploring the efficacy (search 1: efficacy) and safety of Cimicifuga racemosa. In reference to safety, 3 searches were conducted in order to identify both studies with results regarding the general safety (frequency and severity of adverse effects) as well as studies investigating the safety in regard to estrogen-sensitive organs (breast, uterus) and the liver.

The search was executed via a free text search using keywords linked with AND/OR/NOT-operators as well as in combination with the corresponding keywords (e.g., Medical Subject Headings) of the corresponding database. Used keywords were Cimicifuga racemosa/Traubensilberkerze/black cohosh/Actaea racemosa, clinical trial/clinical study/klinische Studie, Review/meta analysis/Meta Analyse, efficacy/Wirksamkeit, side effect/Nebenwirkung/adverse reaction/adverse drug/adverse event/adverse effect/ADR/ UAW/interaction/Interaktion/Wechselwirkung/safety/Sicherheit/toxicity/Toxizität/intoxication/Intoxikation/poison, breast/Brust/mamma/uterin/uterus/Gebärmutter/tumor/tumour/cancer/hormon/estrogen/Östrogen, Leber/liver/hepat, case report/Fallstudie.

In order to ensure the currentness of the evidence, the range of the publications was limited to the years 2000-2012.

2.2. Selection of Publications. The search results were preselected based on their titles and abstracts. Criteria for inclusion and exclusion were predetermined (Table 1). References, which were considered potentially relevant, were then viewed as full text. The result of the first selection included all references, which suggested meeting the inclusion and exclusion criteria. A final assessment occurred after the full texts had been submitted to the secondary selection. If full texts were available, furthermore a supplemental manual search was performed within the bibliography of the publications.

The data obtained from the secondary selection of the included references were assessed and evaluated in summary based on their methodology and the quality of their studies.

2.3. Inclusion, Exclusion, and Stratification Criteria. For the assessment of the efficacy, this review only lists clinical studies in which women with neurovegetative and/or psychic climacteric complaints were treated with the investigated phytopharmaceutical for a minimum of 3 months. For a complete assessment of the evidence, the criterion "clinical study" included all types of studies (randomized/controlled, metaanalyses of randomized/controlled studies, open/controlled, open/uncontrolled, case-control studies, and epidemiological cohort studies). In reference to the safety assessment, the duration of treatment was not limited. In the controlled studies, the comparative interventions included placebo, hormone preparations/tibolone, fluoxetine, and different dosages of the study preparation as well as the comparison of a Cimicifuga mono-preparation versus a combination of the same extract with another active ingredient. For the assessment of the efficacy of interventions against climacteric complaints, placebo-controlled studies are essential. Therapy regimes with hormones/tibolone were also included as comparative intervention, since these are standard therapies for climacteric complaints. In recent years, effects of selective serotonin-reuptake inhibitors against vasomotor and psychic climacteric complaints have been described; therefore, this comparative intervention has also been included.

We did not conduct any explicit search on the effect (preclinical studies, mode of action). Secondary literature such as reviews, general surveys, comments, discussions, and conference presentations as well as the description of individual case reports/casuistics have been excluded. 
TABLE 1: Inclusion, exclusion, and stratification criteria for the identification of the literature for the evaluation of the efficacy and safety of Cimicifuga racemosa.

\begin{tabular}{|c|c|c|c|c|}
\hline & Efficacy & $\begin{array}{c}\text { General } \\
\text { safety }\end{array}$ & $\begin{array}{c}\text { Safety in } \\
\text { estrogen-sensitive } \\
\text { organs }\end{array}$ & $\begin{array}{l}\text { Liver } \\
\text { safety }\end{array}$ \\
\hline \multicolumn{5}{|l|}{ Inclusion criteria } \\
\hline (1) Medical application of Black Cohosh & + & + & + & + \\
\hline (2) 3-month treatment period at a minimum & + & & & \\
\hline (3) Full publication of clinical studies & + & + & + & + \\
\hline (4) Efficacy in natural climacteric complaints (neurovegetative, psychic) & + & & & \\
\hline (5) Occurrence and frequency of adverse events & & + & + & + \\
\hline (6) Influence on hormone parameters, breast, and uterus & & & + & \\
\hline (7) Influence on liver function parameters & & & & + \\
\hline \multicolumn{5}{|l|}{ Exclusion criteria } \\
\hline (1) Preparations containing more than two ingredients & + & + & + & + \\
\hline (2) Medication-induced complaints (e.g., tamoxifen) & + & & & \\
\hline $\begin{array}{l}\text { (3) Use outside the registered indication (bone metabolism, anxiety disorder, and } \\
\text { cognition) }\end{array}$ & + & + & + & + \\
\hline (4) Prevention, including tertiary prevention of sequelae & + & & & \\
\hline (5) Publications in languages other than English/German & + & + & + & + \\
\hline \multicolumn{5}{|l|}{ Stratification criteria } \\
\hline (1) Sorting by type of extract & + & + & + & + \\
\hline (2) Differentiation between registered medicinal products versus other products & + & + & + & + \\
\hline
\end{tabular}

Clinical studies whose primary endpoint was outside the registered indication for Cimicifuga racemosa (such as bone metabolism, anxiety disorder, cognition, and tamoxifeninduced complaints) were not included in reference to the efficacy. In regard to the question whether Cimicifuga racemosa is a safe treatment option for breast cancer patients with climacteric complaints, studies conducted with these patients were included for assessment. Search results yielding studies with combined preparations containing more than two active ingredients were not included, since a definite attribution of efficacy and safety is not possible for multiple-substancecombinations.

Patient-relevant endpoints were the reduction of neurovegetative and/or psychic climacteric symptoms, the frequency and severity of adverse events, and the influence on breast/uterus/breast-cancer risk or laboratory values (such as gonadotropins, ovarian hormones, and liver function parameters). A change of the symptomatology was measured based on different scales such as the Kupperman Menopause Index (KMI), the Menopause Rating Scale (MRS), the Hamilton Depression Scale (HAMD), and frequency of symptoms or diverse scales on health-related quality of life. The selection was not limited to certain scales.

Only publications in English or German have been included in this systematic analysis.

A significant point of this review is the differentiation of results both by indication as well as by type of extract and the regulatory status. The results were sorted and reported accordingly.

\section{Results}

3.1. Literature Search on the Efficacy. A total number of 105 references were identified. After reviewing abstracts and full publications, 86 search results were excluded in accordance with the inclusion and exclusion criteria (Figure 1).

19 full publications on a total of 18 clinical studies, which investigated the efficacy of Cimicifuga racemosa for natural climacteric complaints, remain.

3.2. Literature Search on Safety. For the assessment of the safety of Cimicifuga racemosa, 3 individual literature searches (general safety, safety on estrogen-sensitive organs, and liver safety) were conducted. If one of those individual searches yielded references whose content matched one of the other individual searches, these were allocated accordingly.

3.2.1. Literature Search on General Safety. A total of 134 references were identified. According to the inclusion and exclusion criteria, 106 of these search results were excluded (Figure 2(a)). In the end, we had found 28 publications concerning the general safety of Cimicifuga racemosa. Furthermore, we found 1 additional publication, which however exclusively deals with general safety, in our search regarding the drug safety in estrogen-sensitive organs.

Additionally, 2 publications were related to questions of drug safety in the liver and another 7 publications to the safety on estrogen-sensitive organs. Six publications additionally involved aspects of safety both in the liver and estrogensensitive organs. 


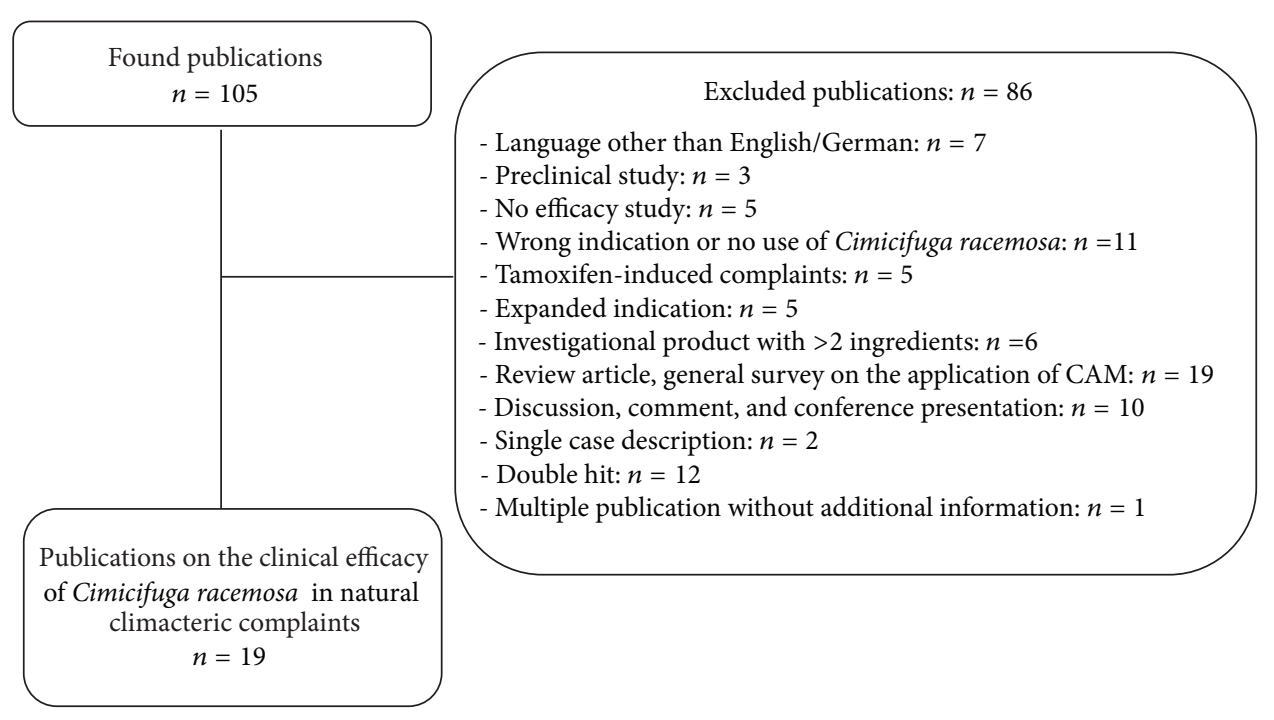

FIGURE 1: Results of the literature search on efficacy.

3.2.2. Literature Search Concerning Safety on Estrogen-Sensitive Tissue. A total of 83 references were identified. As per the inclusion and exclusion criteria, 69 references were excluded (Figure 2(b)). Fourteen publications concerning the safety of Cimicifuga racemosa in reference to estrogensensitive organs remained.

In addition, 4 of these publications also gathered data on general safety and 3 on the liver safety as well as general safety.

3.2.3. Literature Search Concerning Liver Safety. Of initially 125 references, 117 were excluded as per the inclusion and exclusion criteria (Figure 2(c)). Eight publications remained, of which 7 referred to clinical studies. Furthermore, we found one meta-analysis of randomized, controlled studies.

Two of the publications additionally contained data on the general safety. Four publications contained additional data both on the general safety and the safety on estrogensensitive organs.

\subsection{Summary of the Results of the Literature Search}

3.3.1. Efficacy. In total, 19 publications from 18 clinical studies have been identified, in which 10,284 patients were treated with Cimicifuga racemosa against natural climacteric complaints. Of these, in 15 clinical studies 10,121 patients $(98.5 \%)$ were treated with a registered medicinal product, while in 3 studies a total of 163 patients (1.5\%) was treated with Cimicifuga-products that had not been registered as medicinal products.

Concerning the special isopropanolic Cimicifuga racemosa extract (iCR), 9 original publications resulting from 9 clinical studies were found [18-26]. Two of these publications investigated the combination of iCR and St. John's Wort in comparison to the monotherapy with iCR [25] or placebo, respectively [26]. Both preparations are medicinal products registered in several countries. In these 9 studies, a total of 9,391 patients were treated with iCR, 6,126 patients with the monotherapy and 3,265 patients with the combination preparation. Thus, more than $91 \%$ of all patients treated in clinical studies with Cimicifuga racemosa received the iCRextract.

Furthermore, 1 publication of a clinical study conducted with a combination of Cimicifuga racemosa and St. John's Wort, which is distributed in Korea as medicinal product, has been found [27]. In this study, 47 patients were treated with the preparation. The publication did not contain any information on the extractant.

Three publications on a total of 2 clinical studies could be identified for the ethanolic extract BNO 1055 [28-30]. This is a medicinal product that has been registered in several countries. In both studies together, a total of 420 patients ( $4 \%$ of all patients treated in clinical studies) were treated with the preparation.

Furthermore, 3 individual studies on different ethanolic extracts, which all have been registered as medicinal products, have been found. These include the extract $\mathrm{Ze}$ 450 (registered in Switzerland) [31], a standard extract for generics (Cr 99) [32], and a Turkish preparation [33]. In these studies, 120,83 , or 60 patients, respectively, were treated with the corresponding preparation.

Furthermore, 3 individual studies conducted with USAmerican Cimicifuga preparations without marketing authorisation as medicinal products have been identified. These concerned one preparation whose extractant was not mentioned [34], one ethanolic extract [35], and one ethanolic extract, which was exclusively used as study medication [36]. The brand name for the unspecified extract can be found among US-American Cimicifuga food supplements. In the individual studies, 61, 80, or 22 patients, respectively, were treated with the individual Cimicifuga preparations.

3.3.2. Safety. A total of 41 full publications have been identified, which are based on 35 clinical studies and one 


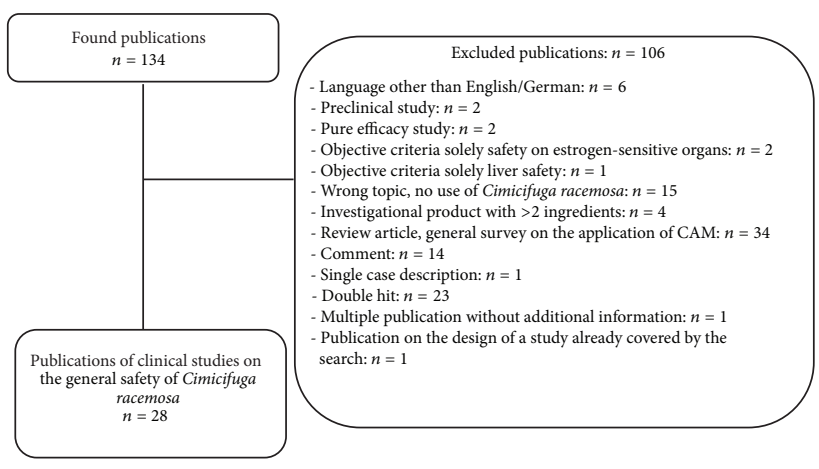

(a)

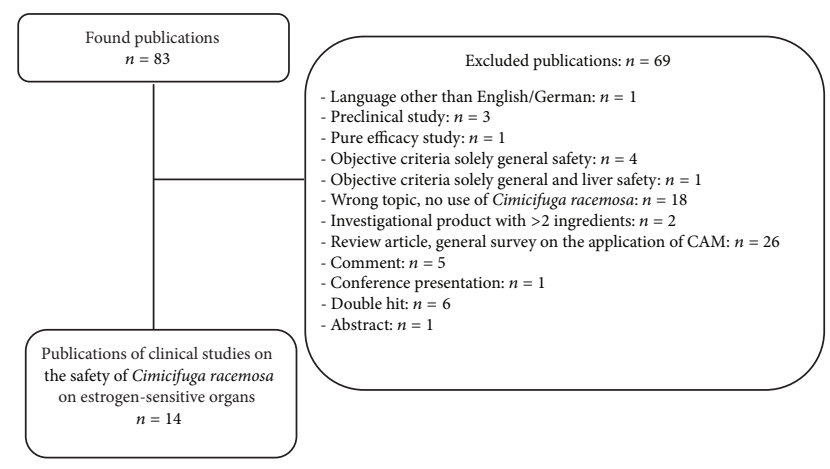

(b)

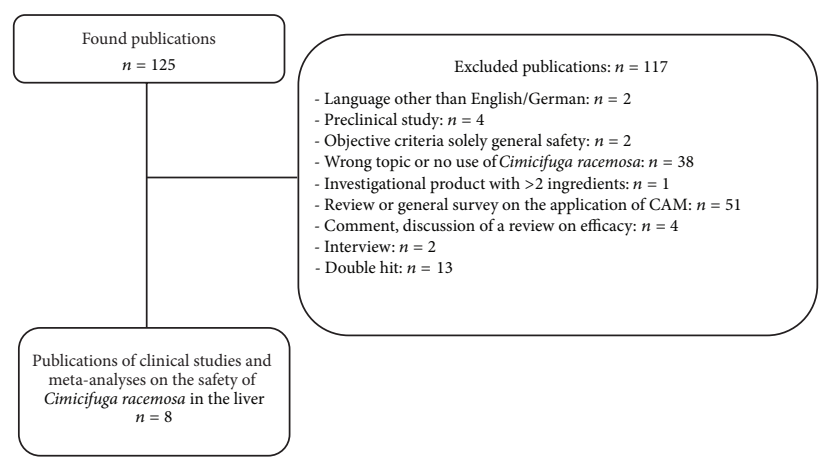

(c)

FiguRE 2: (a) Results of the literature search on general safety. (b) Results of the literature search on safety on estrogen-sensitive tissue. (c) Results of the literature search on liver safety.

meta-analysis of 5 published randomized, controlled studies. The publications furthermore include 5 reanalyses of clinical studies with additional information. Twenty-five clinical studies as well as the meta-analysis concerned registered medicinal products, 10 studies concerned unregistered products or preparations with unknown regulatory status or unspecified preparations. Within the context of these clinical studies, safety-relevant aspects were studied in a total of 13,492 users of Cimicifuga racemosa. Among those, 11,961 patients $(88.6 \%)$ received registered medicinal products, 1,531 patients (11.4\%) used Cimicifuga preparations not registered as medicinal products or unspecified preparations.

Concerning the isopropanolic Cimicifuga racemosa extract (iCR), we retrieved a total of 19 publications [18-23, 25, 26, 37-47]. Two of these investigated the combination of iCR and St. John's Wort in comparison to monotherapy with iCR [25] or placebo [26], respectively. The 19 publications are based on 17 clinical studies and 1 meta-analysis of 5 randomized, controlled studies already identified through the search [37]. One publication covers the second analysis of mammogram findings from a clinical study and their comparison with the findings from a comparable patient cohort obtained within the context of a placebo-controlled study with hormone therapy and tibolone [38]. On the whole, 11,054 patients $(81.9 \%)$ were treated in the clinical studies with iCR, 7,789 with the monopreparation and 3,265 with the combination.

For the Korean combination preparation from Cimicifuga racemosa and St. John's Wort, the publication we already identified for the aspect "efficacy" also delivers safety-relevant information [27].

Regarding the ethanolic extract BNO 1055, 6 publications have been identified, which are based on 4 clinical studies [28-30, 48-50]. In these studies, a total of 597 patients $(4.4 \%)$ were treated with the preparation.

The 3 studies already identified in the efficacy search for other registered preparations with ethanolic extracts also covered safety aspects [31-33].

Ten clinical studies refer to (mostly US-American) products not registered as medicinal products. These include the 3 publications already identified in the efficacy search [34-36], which also described safety-relevant aspects. Regarding the study of Newton et al. [35], 2 second analyses have been published [51, 52]. Furthermore, 2 publications on ethanolic extracts have been identified $[53,54]$ as well as 5 publications on extracts whose extractant has not been specified [55-59].

In 2 publications found for the isopropanolic extract (iCR), some patients, in addition to those who were treated with iCR, were treated with extracts, which were not specified in detail $[45,46]$.

\section{Discussion}

4.1. Answering the Question of Efficacy. Based on current, GCP-compliant studies and a clear separation by extracts and indications, today's response to the question of efficacy is highly differentiated. 
When differentiating by regulatory status, it becomes obvious that all registered medicinal products containing Cimicifuga racemosa investigated in clinical studies uniformly demonstrate as a minimum exploratory evidence for their efficacy. In particular the isopropanolic extract (iCR) as monotherapy and in combination with St. John's Wort as well as the Korean Cimicifuga-St. John's Wort combination actually yielded confirmatory evidence for their efficacy. In contrast, US-American extracts, not registered as medicinal products, in the majority (2 out of 3 studies) could not yield any evidence for efficacy (Table 2). Evidence for efficacy clearly and significantly depends on the regulatory status as medicinal product, when analyzing the totality of all studies as well as when only analyzing those studies designed for confirmatory evidence (Tables 3(a) and 3(b)).

As early as in the 1980s, several clinical studies investigated the efficacy and safety of the first Cimicifuga preparation introduced in Germany in 1956 (Remifemin) for the indication of climacteric neurovegetative complaints [60]. Although the studies were conducted in a time period prior to the introduction of good clinical practice- (GCP-) criteria and prior to the publication of the monograph for Cimicifuga racemosa by the German Commission E [61], the "old" study results are clearly confirmed by the results of the "new" GCPcompliant studies.

Only 2 extracts were investigated in several GCPcompliant clinical studies for their efficacy. These are the isopropanolic extract iCR (9 publications from 9 studies with a total of 9,391 patients) and the ethanolic extract BNO 1055 (3 publications from 2 studies with a total of 420 patients). For both extracts therefore not only Levels of Evidence but also Oxford Grades of Recommendation can be derived. For all other extracts only one individual publication each is available.

4.1.1. Medicinal Products with the Isopropanolic Extract (iCR). The efficacy of the iCR extract has been proven by 4 randomized, controlled studies $[18,20,21,26]$ and is further supported by 2 controlled as well as 3 uncontrolled studies with proof of efficacy as primary objective [19, 22-25].

A significantly superior improvement of climacteric complaints was demonstrated in a total of 304 patients after 3 months of treatment with the standard dose of iCR (40 mg) versus placebo. The superiority was especially significant in women in menopausal transition, and the strongest effect could be achieved for vasomotor complaints [18]. In comparison to low-dose transdermal hormone therapy in a total of 64 women, a comparably strong, significant improvement of vasomotor complaints, anxiety and depression could be achieved after 3 months [21]. Furthermore, in 3 months of therapy, a strong, significant improvement in the Kupperman Menopause Index, comparable to tibolone, was achieved in 244 Asian women. Since the iCR extract in this investigation, however, had the better safety profile, it was superior to tibolone in the benefit-risk profile [20]. After 3 months of treatment with the iCR extract, responder rates reached approximately $70-80 \%[19,20]$.
In addition to vasomotor symptoms, many menopausal women also suffer from psychic complaints such as nervousness, irritability, anxiety, restlessness, or depressive moods $[62,63]$. In these patients especially, the combination of St. John's Wort and Cimicifuga extract has been successfully used in clinical practice for decades. These clinical experiences have been confirmed by controlled clinical studies. In a randomized, controlled study in 301 women, the combination of iCR and St. John's Wort was used for 4 months. In comparison to placebo, both the Menopause Rating Scale as well as the Hamilton Rating Scale for Depression improved significantly [26]. In a controlled study with 6,141 patients who were treated for 6 months (or 736 patients who were treated up to 12 months, resp.), the combination of iCR and St. John's Wort proved to be significantly more effective than the iCR-monotherapy for psychic climacteric complaints [25].

Two larger, uncontrolled studies, in which 502 or 2,016 women, respectively, were treated for 3 months, demonstrated significant improvements of the Kupperman Menopause Index, which were most pronounced for vasomotor complaints $[22,23]$. Another, uncontrolled study in 122 patients demonstrated a significant increase in the quality of life after 3 months of treatment [24].

The randomized, controlled studies [18, 20, 21, 26] all qualify for an Oxford Level of Evidence 1b. Due to the consistent Level-1 data, a Grade of Recommendation A can be stated [17] (Figure 3).

4.1.2. Medicinal Products with the Ethanolic Extract BNO 1055. Exploratory efficacy of this extract was demonstrated in a randomized, controlled study with a small case number, on which a reanalysis has been published $[28,29]$. It has also been supported by a uncontrolled study [30].

In the controlled study with a total of 62 women, the improvement in the Menopause Rating Scale (MRS) for the ethanolic Cimicifuga extract was comparable to a hormone preparation versus placebo after 3 months. Due to the small case number ( $n=20$ in the Cimicifuga group), however, it just stayed below the level of significance. In the exploratory reanalysis, however, a significant superiority versus placebo in reference to daily sweats, waking at night, and the MRSsubscores major climacteric complaints, somatic complaints, and mental score could be demonstrated.

The uncontrolled study investigated the safety of the extract in the endometrium in 400 women for 12 months and also demonstrated a significant improvement of the Menopause Rating Scale II and the MRS II 4-week weighted score of hot flushes.

The controlled study of low quality yielded sufficient evidence for an Oxford Level of Evidence 2b. Due to the consistent Level-2 data, a Grade of Recommendation B may be postulated (Figure 3).

4.1.3. Further Extracts with Marketing Authorization as Medicinal Product. For 4 further Cimicifuga medicinal products (three mono preparations and one combination with St. John's Wort) each with one publication of a randomized, 


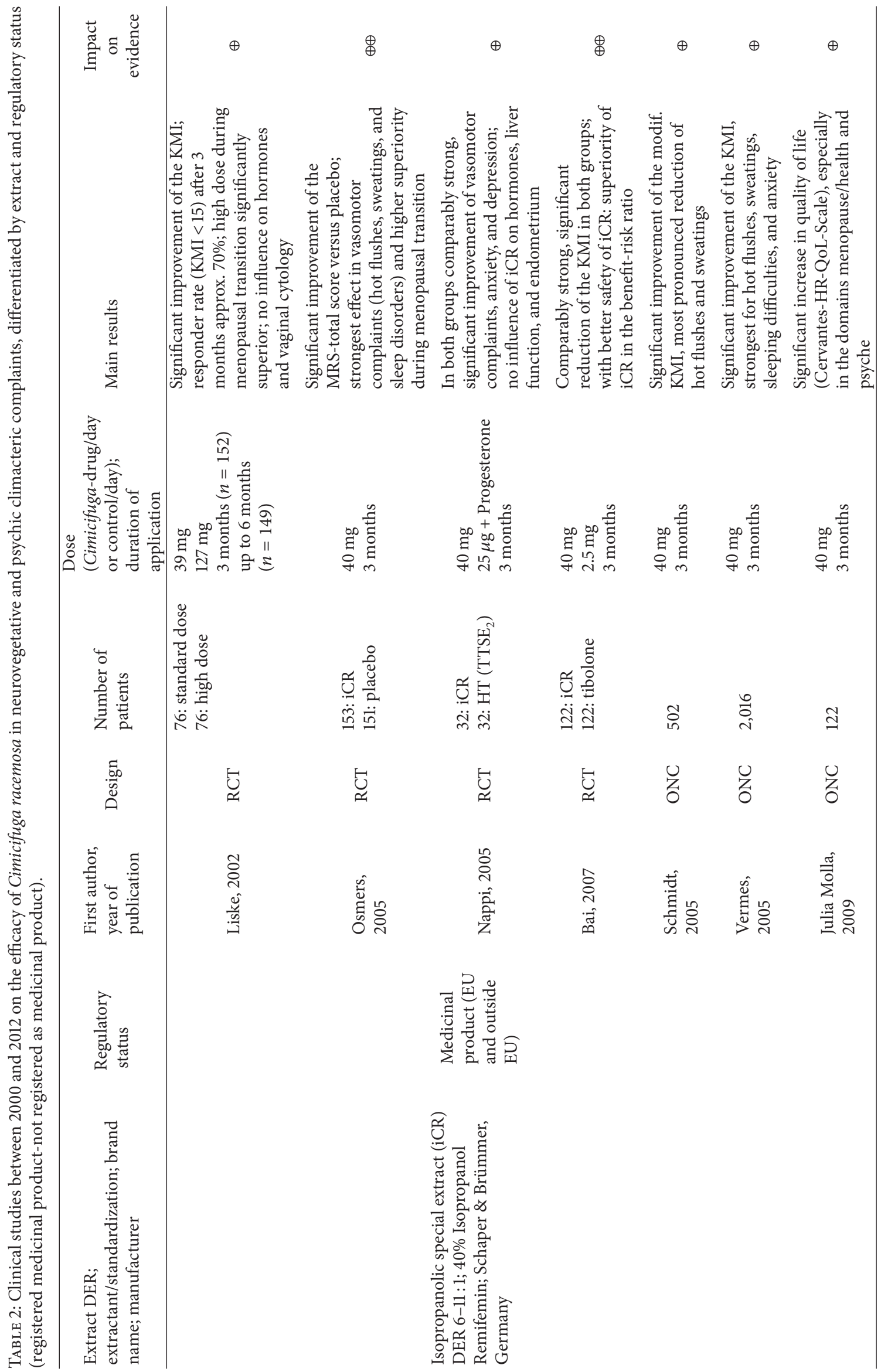




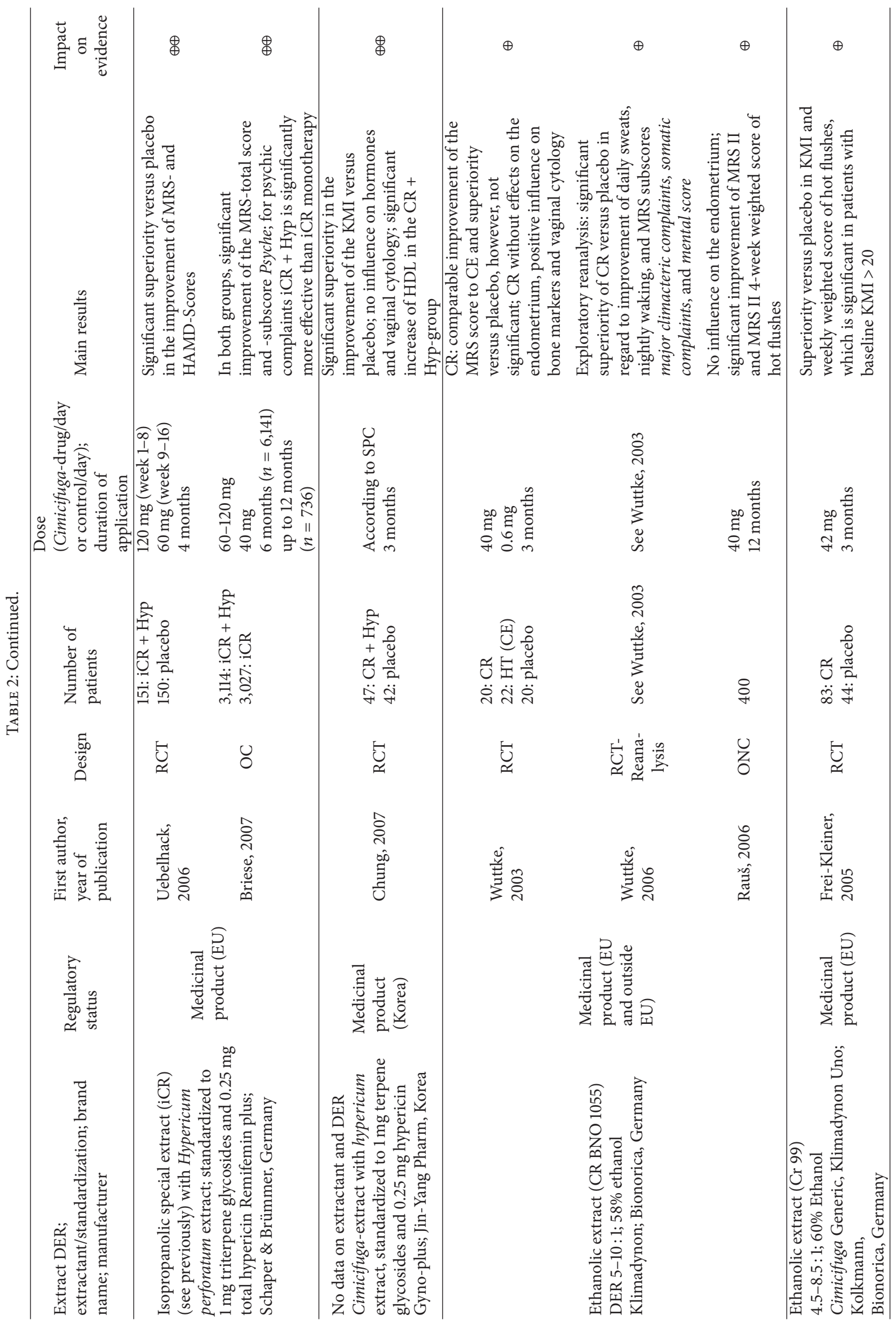




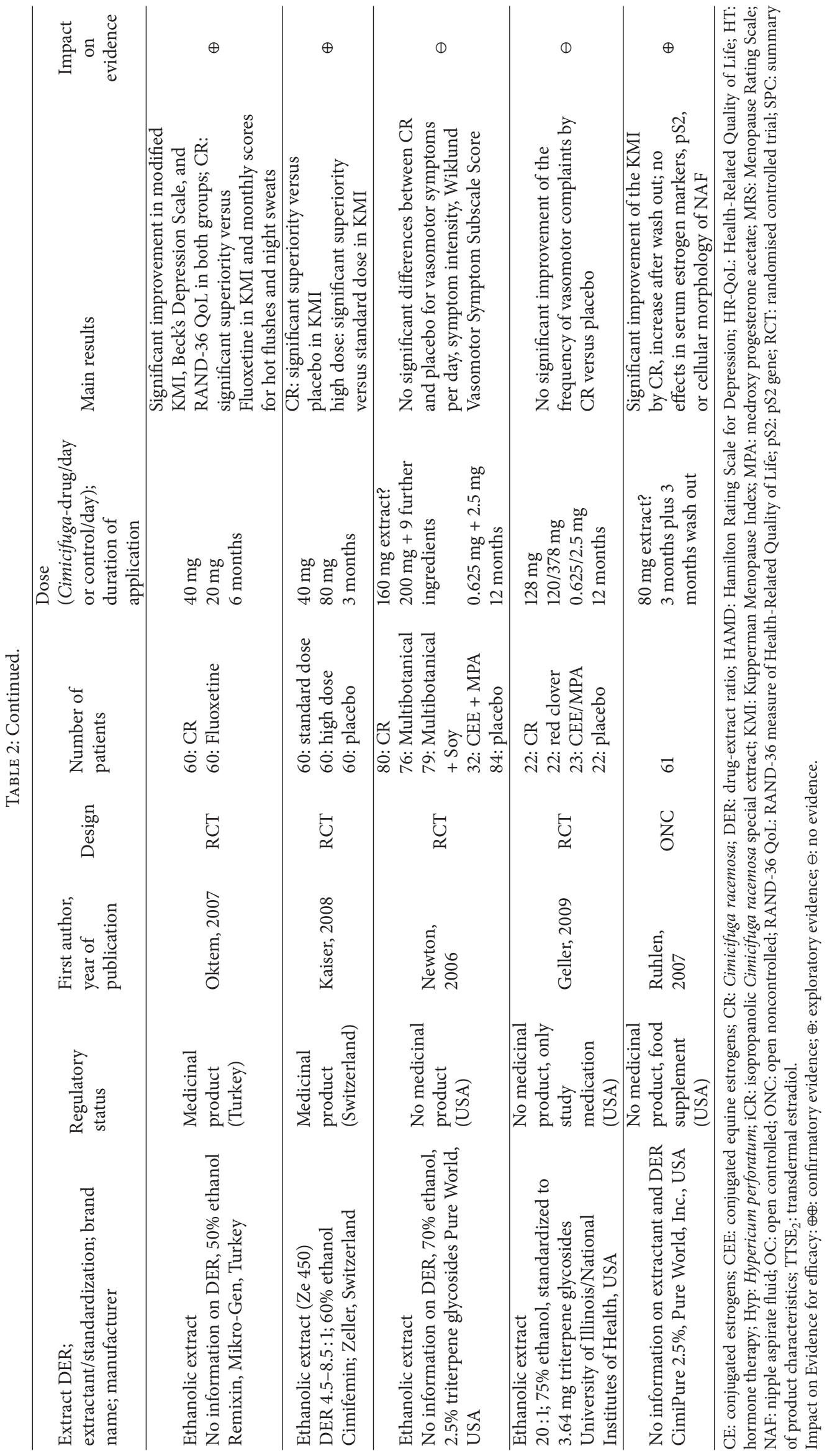




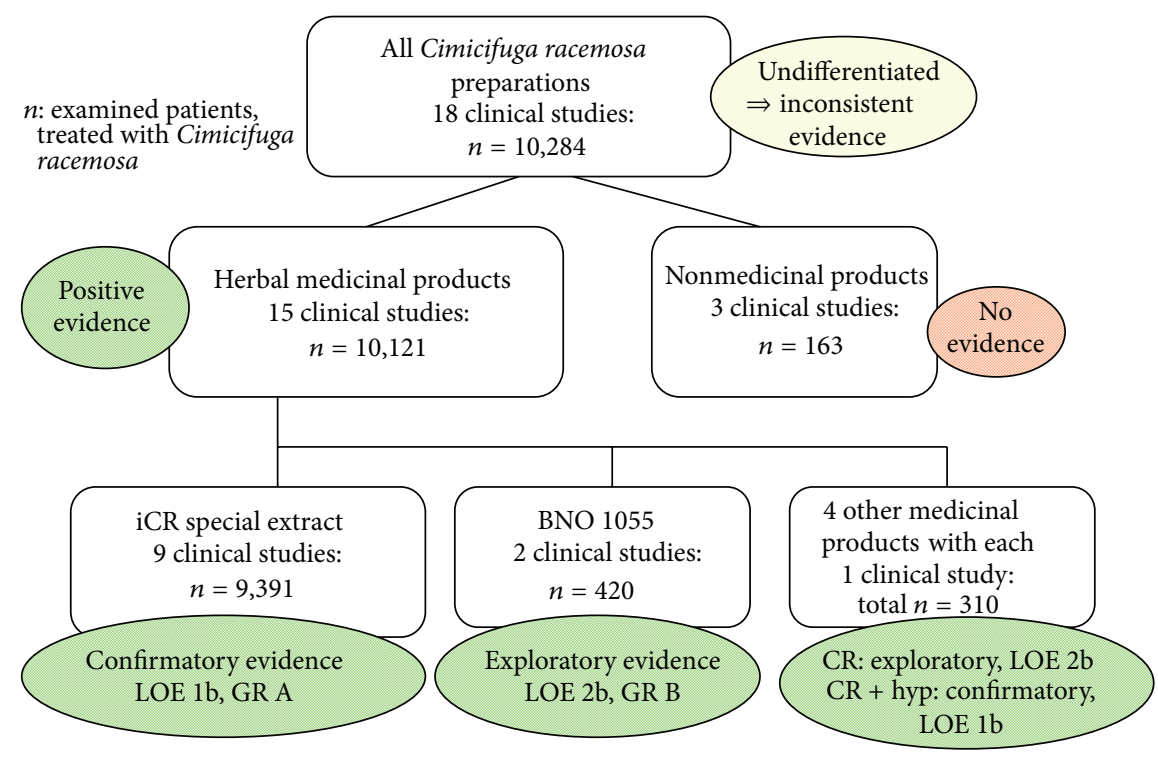

Figure 3: Efficacy data on Cimicifuga racemosa 2000-2012.

TABLE 3: Evidence for efficacy depends on regulatory status.

(a)

\begin{tabular}{lcc}
\hline \multirow{2}{*}{ All studies } & \multicolumn{2}{c}{ Registered herbal medicinal product } \\
& Yes & No \\
\hline Evidence for efficacy & 15 & 1 \\
$\quad$ Yes & 0 & 2 \\
No & & \\
\hline
\end{tabular}

$n=$ number of studies, $P=0.0008$ ( $\mathrm{Chi}^{2}$-test $)$.

(b)

\begin{tabular}{lcc}
\hline Subset of confirmatory studies & $\begin{array}{c}\text { Registered herbal medicinal } \\
\text { product }\end{array}$ & No \\
\hline Evidence for efficacy & Yes & \\
$\quad$ Yes & 5 & 0 \\
No & 0 & 2
\end{tabular}

$n=$ number of studies, $P=0.008$ ( $\mathrm{Chi}^{2}$-test).

Registered $=$ holding a marketing authorization .

controlled study, confirmatory (combination preparation) or at least exploratory evidence (mono preparations) for their efficacy was demonstrated.

After 3 months of therapy in a total of 180 women, the ethanolic extract Ze 450 was significantly superior versus placebo in the Kupperman Menopause Index. Furthermore, a higher dosage proved to be more effective in comparison to the standard dose [31]. The ethanolic extract Cr 99 was able to demonstrate its superiority versus placebo in the Kupperman Menopause Index and in the weekly weighted score of hot flashes after a 3-month therapy in a total of 125 women. The superiority was only significant, however, in a subgroup of women who suffered from stronger complaints
(KMI > 20) at the beginning of the study [32]. An extract registered as a medicinal product in Turkey (ethanolic as per manufacturer's homepage) and the control substance fluoxetine demonstrated a significant improvement in the modified Kupperman Menopause Index, Beck's Depression Scale, and the RAND-36-QoL after 6 months in 120 patients. Concerning the improvement of the Kupperman Menopause Index and hot flashes as well as night sweats, the Cimicifugaextract was significantly superior to fluoxetine. In the other scores, fluoxetine proved to be better. The quality of these studies allows to postulate a Level of Evidence 2b (Figure 3).

A Korean combination preparation from Cimicifuga racemosa and St. John's Wort yielded confirmatory evidence for its efficacy after 3 months of use: in comparison to placebo there was a significantly superior improvement in the Kupperman Menopause Index. A total of 89 women participated in this study. This study justifies a Level of Evidence 1b (Figure 3).

4.1.4. Other Extracts without Marketing Authorization as Medicinal Product. For 3 US-American Cimicifuga preparations without marketing authorization as medicinal product, a total of 2 randomized, controlled and 1 open, uncontrolled study could be identified. The dosage information in the publications does not always clearly indicate whether it refers to the amount of extract or drug.

A 5-arm randomized, controlled study was conducted for 12 months with an ethanolic extract in a total of 351 women. Hereby, no significant differences could be found between the Cimicifuga preparation (daily dosage $160 \mathrm{mg}$ ) and placebo [35] in reference to the vasomotor symptoms. A 4-arm randomized, controlled study in a total of 89 women demonstrated no significant improvement of the frequency of vasomotor complaints in comparison to placebo after 12 months of treatment for another ethanolic extract (daily dose $128 \mathrm{mg}$ ) [36]. Merely an open, uncontrolled study in 61 women could demonstrate a significant improvement of 
the Kupperman Menopause Index after 3 months of treatment in comparison to baseline [34].

The controlled studies yielded no evidence for the efficacy of the used Cimicifuga-preparations, which prior to their use had not been subject to any control by regulatory drug approval procedures.

\subsection{Answering the Question of Safety}

4.2.1. General Safety. Of the 41 publications identified in the literature search, 31 investigated aspects relevant for general safety (Table 4). Uniformly and independently from their regulatory status, they demonstrated that extracts from Cimicifuga racemosa have a good to very good tolerability. Overall, no side effects were recorded, which go beyond the known side effects listed in the HMPC monograph [8]. The placebocontrolled studies demonstrated that in regard to frequency and severity of adverse effects, Cimicifuga racemosa does not significantly differ from treatment with placebo $[18,26,28$, $32,35,36]$. As also described in the HMPC-monograph, there are no generally known drug interactions for Cimicifuga racemosa [8]. This has been confirmed by 2 studies which did not find any clinically relevant interaction with cytochrome P-isoenzymes or P-glycoprotein $[55,56]$.

The safety data for the Cimicifuga racemosa preparations investigated in clinical studies can be assessed uniformly and in general confirm the safety of the used preparations.

4.2.2. Safety in regard to Estrogen-Sensitive Tissue. Twenty two of the 41 publications investigated safety-relevant aspects under the therapy with Cimicifuga racemosa in reference to estrogen-sensitive tissues such as breast or uterus (Table 4). Under treatment with Cimicifuga racemosa, no clinically relevant changes of hormonal parameters (e.g., estradiol, FSH, and LH) were detected (e.g., [19, 21, 27, 36, 40, 52]). The endometrium is neither influenced by Cimicifuga racemosa $[20,21,28,30,36,43]$. Mammographic breast density, breast cell proliferation, or cell morphology in the nipple aspirate fluid neither changed under Cimicifuga treatment [30, 34, $36,38,43]$. Some smaller studies in breast cancer patients also demonstrated good tolerability of Cimicifuga racemosa in these patients [39, 41, 44, 49]. Several large case-control studies investigated the influence of Cimicifuga racemosa on breast cancer risk. A publication found no association between the application of Cimicifuga racemosa and breast cancer risk [59]. A US-American study demonstrated that breast cancer risk was reduced in users of Cimicifuga racemosa [46]. A study supported by the German Cancer Aid (Deutsche Krebshilfe e.V.) with more than 9,900 participating women showed no increase in breast cancer risk by ethanolic Cimicifuga racemosa extracts. For the isopropanolic Cimicifuga racemosa extract, this investigation even demonstrated a reduction of breast cancer risk [45]. This result was independent of lifestyle factors, tumor histology and tumor receptor status, and a longer duration of use improved risk reduction. A pharmacoepidemiological cohort study was able to demonstrate a slight reduction in the risk of recurrence for the isopropanolic Cimicifuga racemosa extract $(n=1,102$ compared to $n=17,759$ not treated with iCR) [47].

The entirety of the data clearly contradicts the existence of any estrogenic effects of Cimicifuga racemosa, which had been suggested decades ago. Under therapy, no adverse effects are to be expected on "critical" estrogen-sensitive organs such as breast or uterus. Based on the study results therefore, climacteric complaints in patients with breast cancer in their medical history can be treated with extracts of Cimicifuga racemosa. The most recent HMPC-monograph [8] confirms this assumption, provided that the cancer treating physician knows about the Cimicifuga therapy.

4.2.3. Liver Safety. In 11 of 41 publications, liver function tests were performed and described prior to as well as during or at the end of the treatment with Cimicifuga racemosa extracts (Table 4). On the whole, no clinically relevant changes of liver function tests became evident (e.g., [18, 20, 21, 32, 48, 50, 58]). Also within the context of all the studies, no liver damage was clinically observed as adverse event. Significant evidence is available for the isopropanolic extract in the form of a metaanalysis of 5 randomized, controlled studies, in which liver safety parameters were recorded [37]. None of these revealed significant differences nor indications of a negative influence onto liver functions. An increase in the dosage compared to the HMPC recommendation or an increased duration of use, respectively, also demonstrated no significant effects.

In contrast to the findings from clinical studies, there are individual case reports, which suspect Cimicifuga racemosa within the context of hepatotoxicity. These include reports on food supplements, which are not subject to the same strict quality controls as medicinal products. For food supplements, for instance, impurities and adulterations (such as using cheaper Asian Cimicifuga species) are known [64]. Therefore, the reported suspected cases of liver side effects in connection with food supplements cannot be applied to registered Cimicifuga medicinal products in general.

A first analysis of internationally published and reported cases was conducted by the European Medicines Agency in 2006. It did not yield any certain causality. In 4 of 42 cases known worldwide, the causality was assessed as possible or probable, respectively [65]. A reanalysis of these 4 questionable cases by means of a liver-specific, validated algorithm was able to exclude a causal connection, however [66]. After 2006, further case reports have become known, which have been evaluated by different groups of experts. Depending on the used algorithm, one receives different causality assessments. When using the liver-unspecific Naranjo scale, a causal connection seems possible [67]. If, however, the assessment is based on the use of a liver-specific, validated algorithm, there is hardly any to no evidence at all for a hepatotoxic potential of Cimicifuga racemosa [68-72]. Experts in the field of hepatology point out the shortcomings of the Naranjo-scale as being not liver-specific and not validated for hepatotoxicity. They demand to apply only liverspecific causality assessment methods which are validated for liver toxicity (e.g., the CIOMS scale) in suspected cases of herb-induced liver injury [73]. 


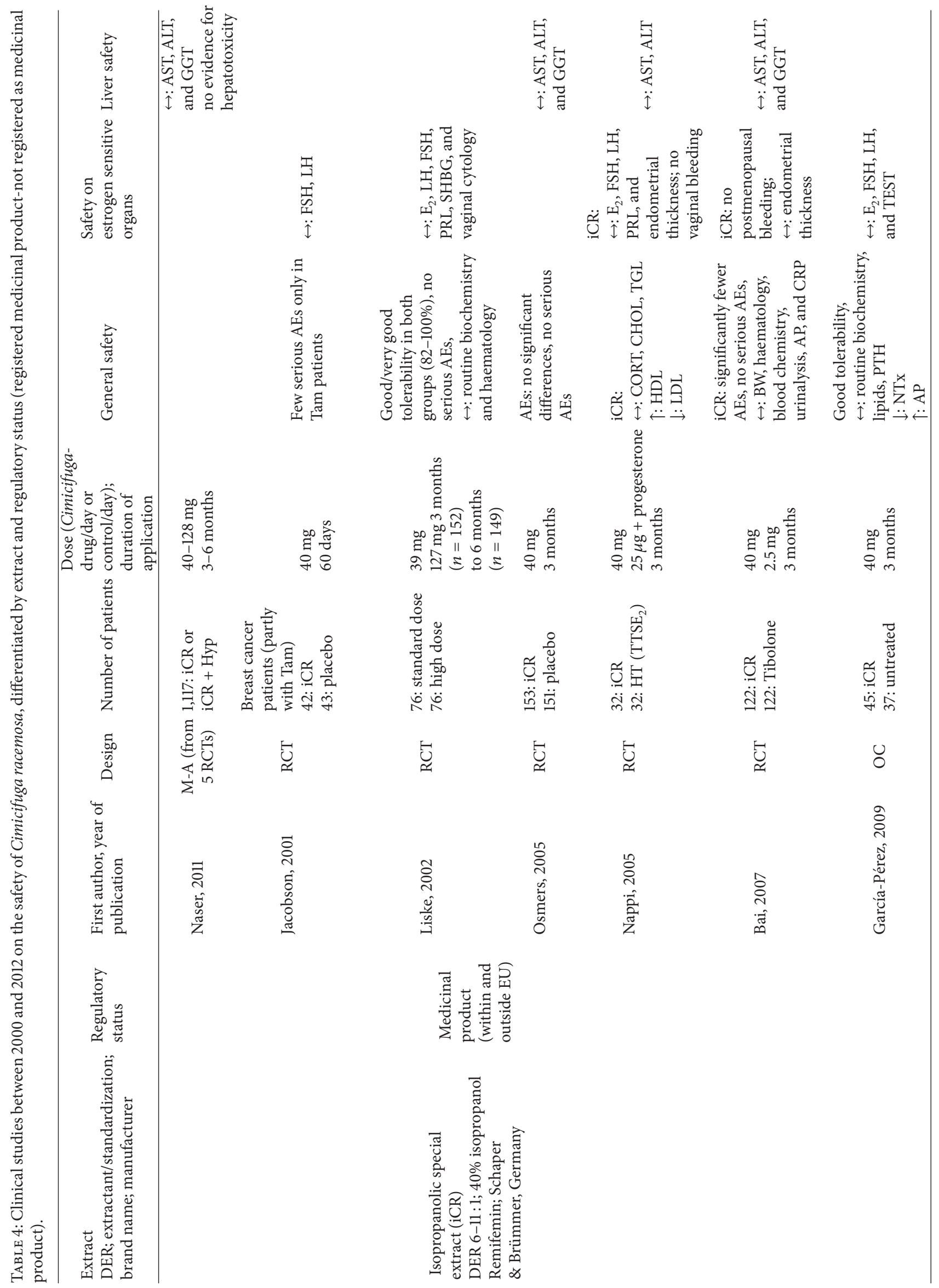




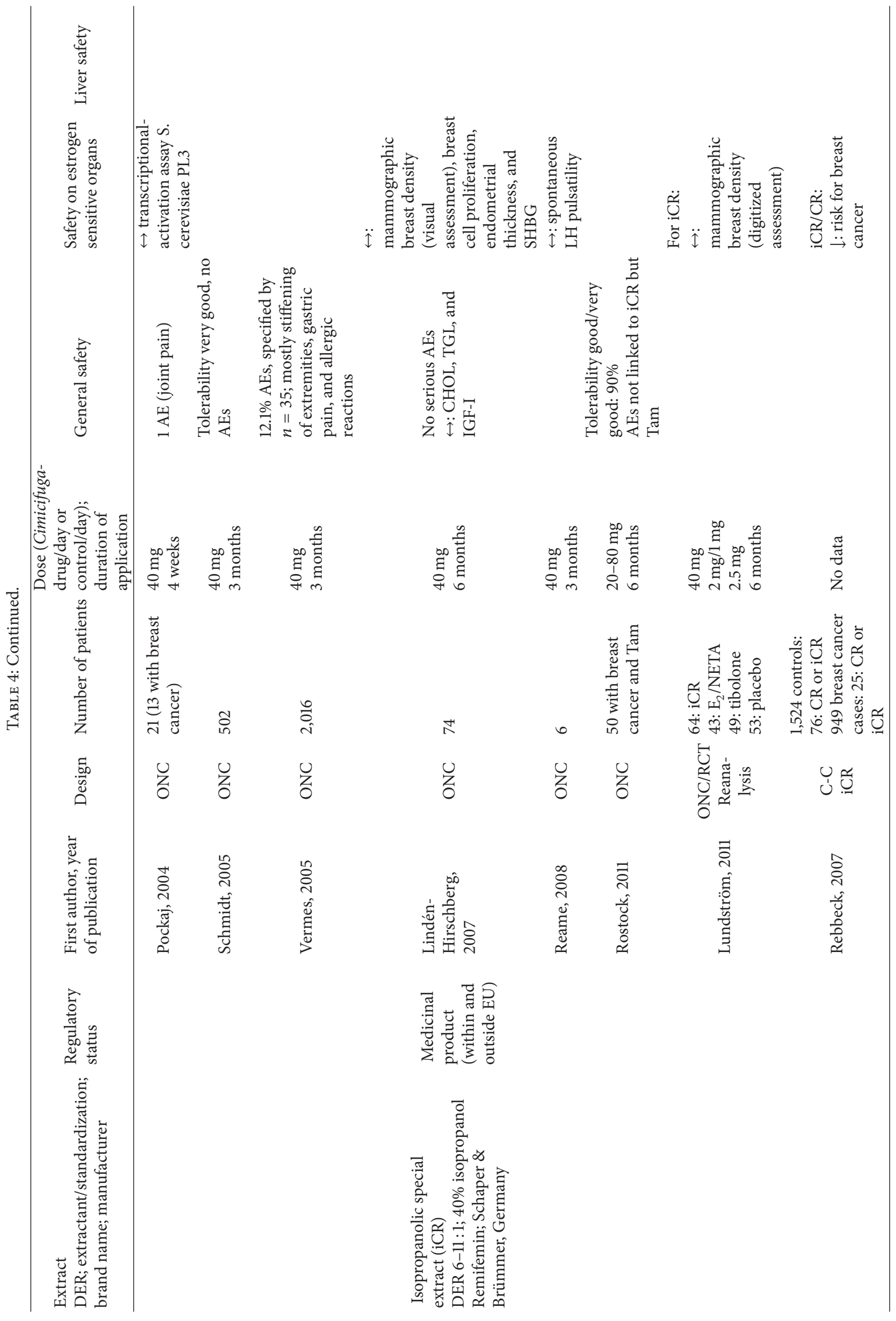




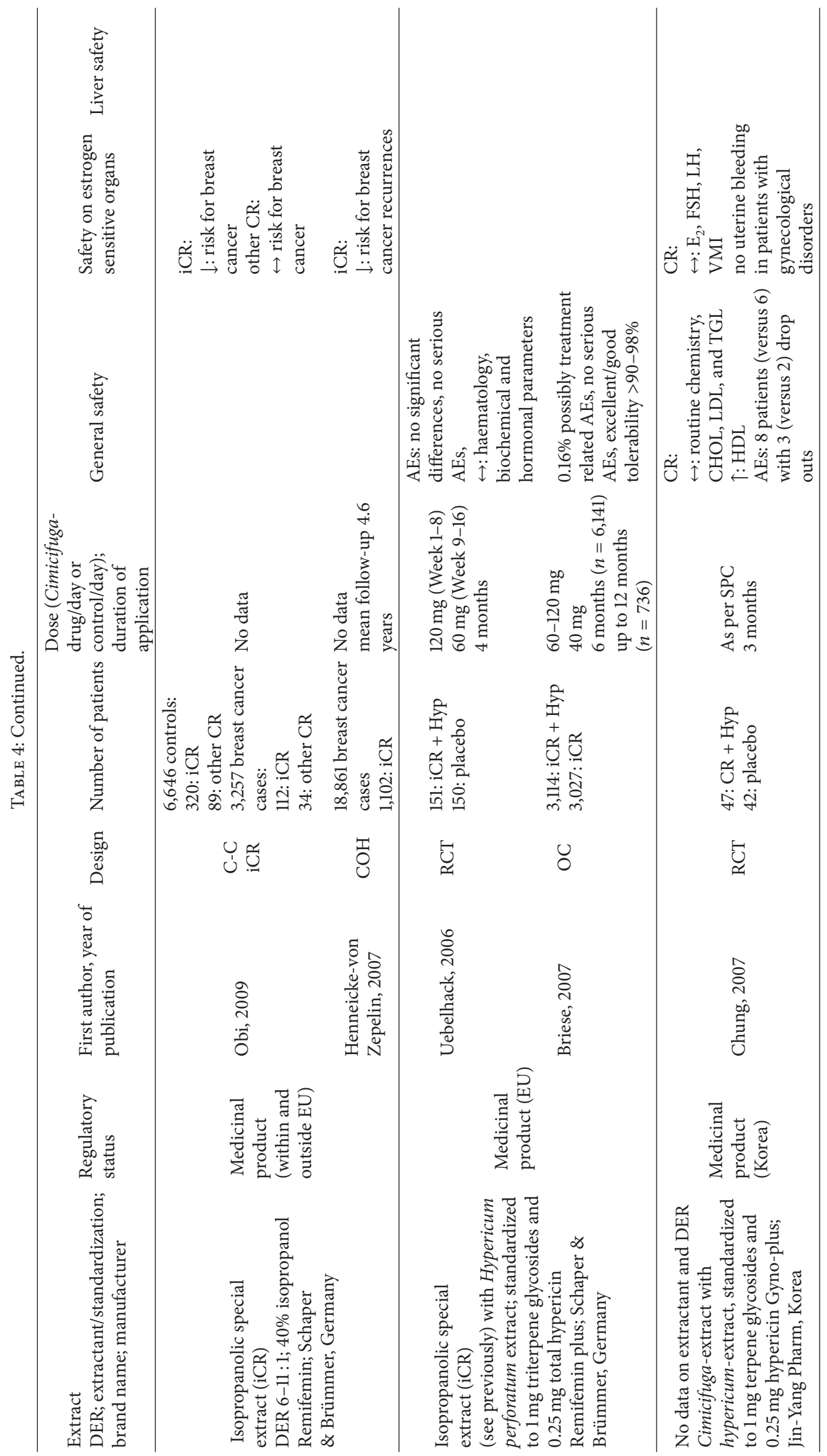




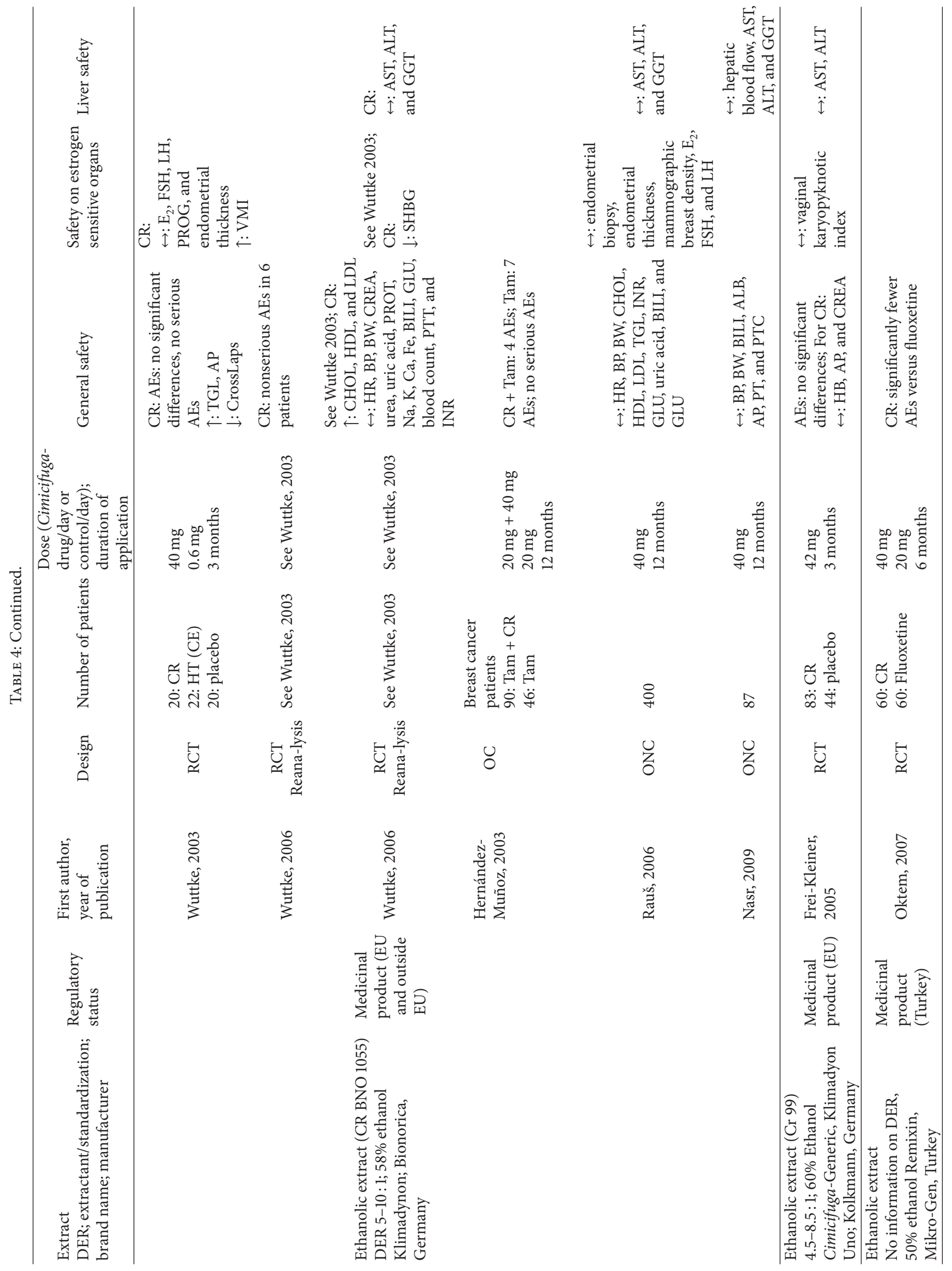




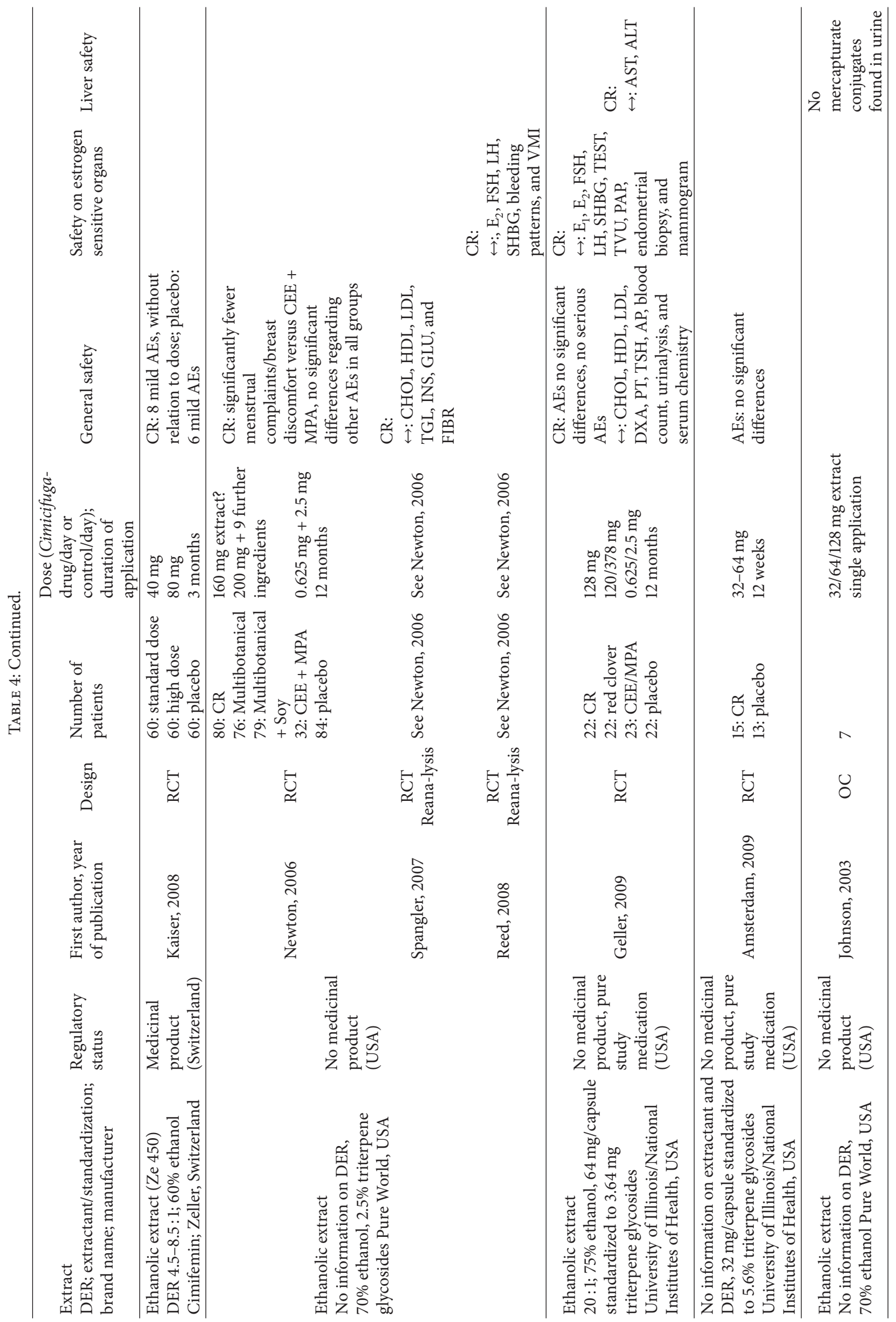




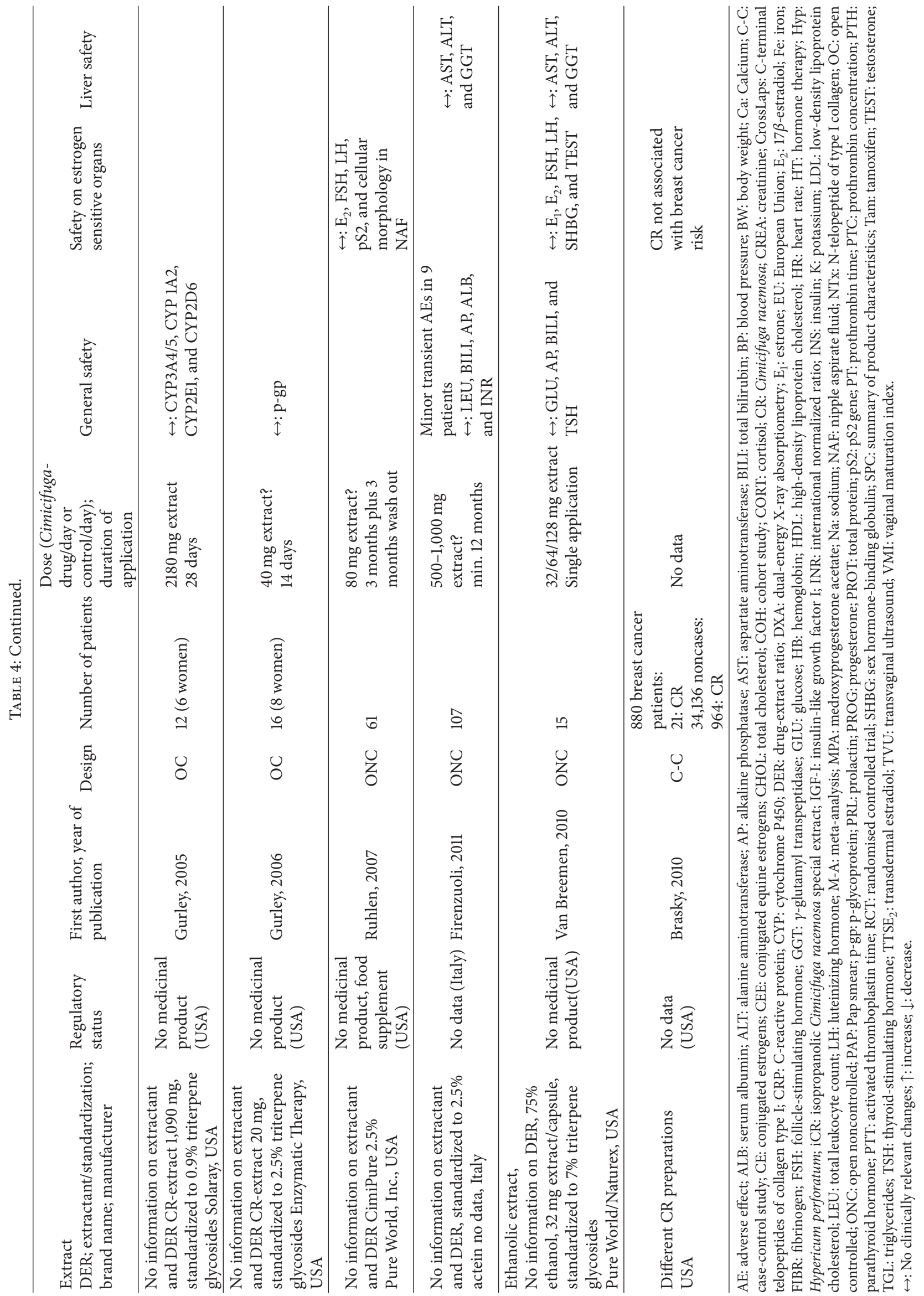




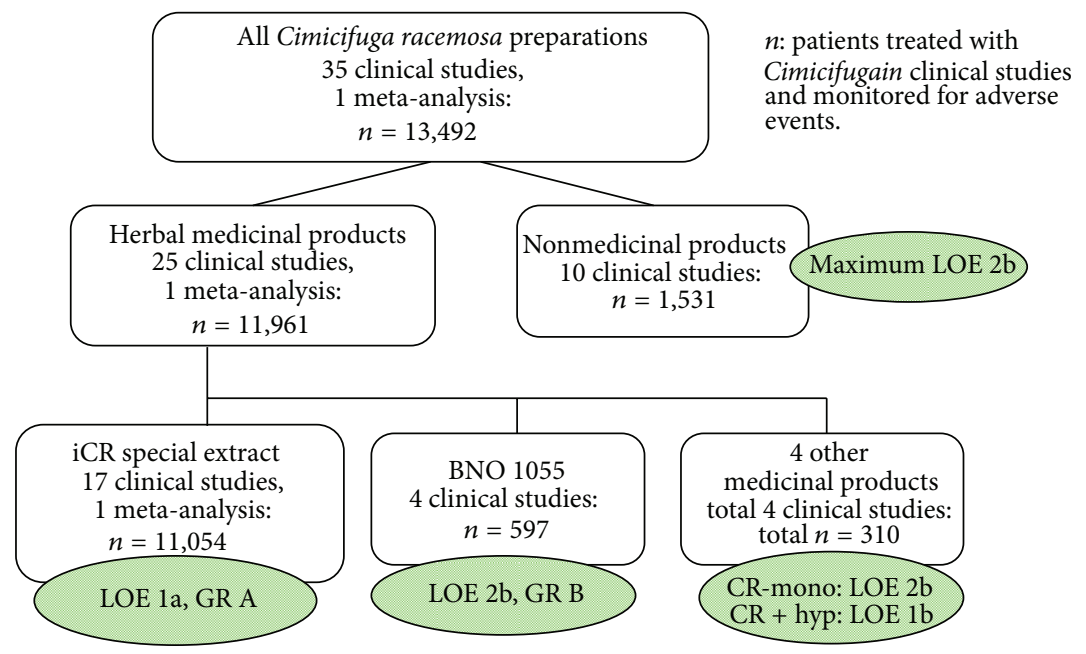

FIgURe 4: Safety data on Cimicifuga racemosa 2000-2012.

4.2.4. Extract-Specific Differences in the Safety Data. From extract to extract, differences have to be taken into consideration in regard to the number of included patients and objectives of the conducted studies.

Of all patients, who were monitored for side effects in clinical studies investigating any Cimicifuga racemosa preparation ( $n=13,492)$, the majority were treated with registered medicinal products $(n=11,961)$. In 1,531 patients no registered medicinal products were used or the preparations were not specified sufficiently, in order to be able to conclude their regulatory status. Among the medicinal products, there were only 2 preparations, which were used in a variety of studies, the isopropanolic Cimicifuga racemosa extract (iCR) and the ethanolic extract BNO 1055.

By far, most patients treated in clinical studies with a medicinal product $(n=11,054)$ received the isopropanolic Cimicifuga racemosa extract (iCR) among which 736 were observed for adverse events for a period of 12 months. Thus, both as monotherapy as well as in combination with St. John's Wort, the iCR extract is the only Cimicifuga extract which fulfills the requirements of the EU guideline ICHE1 (CPMP/ICH/375/95) for the permission of a long-term therapy. For this extract, the state of the evidence is the best: among the 17 publications there are not only several high-quality, randomized, and controlled studies, but also a homogenous meta-analysis of 5 randomized, controlled studies. The safety data for the iCR-extract therefore corresponds to an Oxford Level of Evidence la, and based on the consistent study results a Grade of Recommendation A can be stated (Figure 4).

The ethanolic extract BNO 1055 was administered in altogether 597 patients. Among the publications, there is 1 randomized, controlled study (with low case number and quality, of which 2 exploratory reanalyses have been published), 1 controlled study and two uncontrolled studies. The status of the safety data allows an Oxford Level of Evidence $2 \mathrm{~b}$ and Grade of Recommendation B (Figure 4).
The status of the data of other medicinal products in regard to drug safety corresponds to Oxford Level of Evidence 2b, for the Korean Cimicifuga-St. John's Wort combination to Level of Evidence 1b (Figure 4).

The evidence for the preparations not registered as medicinal products varies, the Level of Evidence regarding safety has to be considered maximally $2 \mathrm{~b}$ (Figure 4 ).

\subsection{Benefit-Risk Profile of Cimicifuga racemosa-Extracts-} Differences between Registered Medicinal Products and Extracts without Marketing Authorization as Medicinal Product. While all Cimicifuga racemosa extracts used in clinical studies demonstrated a good to very good safety profile independently of their regulatory status, this is not the case in regard to efficacy. Here, only officially assessed, registered medicinal products yielded the proof of efficacy. All Cimicifuga medicinal products could at least prove exploratory efficacy for the registered indication of neurovegetative and psychic climacteric complaints, and the isopropanolic extract (iCR) and a Korean medicinal product additionally yielded confirmatory evidence. Consistent investigations have been conducted for the isopropanolic iCR-extract and the ethanolic BNO 1055 extract, so that for these extracts Grades of Recommendation can be determined (iCR: LOE 1b, GR A; BNO 1055: LOE 2b, GR B). Both extracts are contained in high-quality medicinal products, which were originally registered in Germany, but in the meantime have been registered internationally. For several products without marketing authorization and therefore without quality approval by regulatory authorities, quality deficiencies may be the reason for the deviating results regarding efficacy. Short descriptions of product quality cannot replace extensive product specifications of drug registration dossiers. The quality of a herbal medicinal product depends on optimally concerted procedures applied from herbal substance to the final product. Optimization of procedures and thereby product quality clearly benefits from decades of technical expertise. For example, the oldest 
herbal medicinal Cimicifuga racemosa product (marketed since 1956) is manufactured according to standardized procedures, which are part of the descriptions in drug registration dossiers. These are approved by regulatory authorities in a multitude of different countries, but not accessible to the public. Available data on this long-standing product is consistently positive.

It is important to differentiate between clinical trials with standardized registered herbal remedies whose pharmaceutical quality has been checked by regulatory authorities and clinical trials with other products.

\section{Conclusion}

Ideally, therapeutic decisions should be based on consistent scientific evidence. Consistently positive data regarding efficacy and safety have clearly been demonstrated for the isopropanolic Cimicifuga racemosa extract (iCR) and the ethanolic extract (BNO 1055) in the treatment of natural climacteric complaints. A multitude of clinical studies including more than 11,000 patients has been identified for the iCR extract, which demonstrates not only a good safety profile but also consistent confirmatory evidence for efficacy. Several clinical trials including more than 500 patients were identified for the BNO 1055 extract, demonstrating a good safety profile and consistent exploratory evidence for efficacy. Both extracts are in compliance with the recent Cimicifuga racemosa monograph of the Herbal Medicinal Products Committee and the corresponding preparations are registered as herbal medicinal products in many countries in and outside Europe.

This is the first review of a herbal treatment option based on a differentiation by extract and indication and therefore meets the distinctive characteristics of phytotherapy. The evidence concerning efficacy is favorable and consistent only for those Cimicifuga racemosa products which hold a marketing authorization for the treatment of climacteric complaints.

\section{Disclosure}

Professor Dr. A.-M. Beer held a lecture at the Congress of the Deutsche Gesellschaft für Gynäkologie und Geburtshilfe (DGGG) in 2012, supported by the company Schaper \& Brümmer. Dr. A. Neff declares no conflict of interests.

\section{References}

[1] Deutsche Gesellschaft für Gynäkologie und Geburtshilfe e.V. Hormontherapie in der Peri- und Postmenopause (HT). Interdisziplinäre S3-Leitlinie. Stand, 2009.

[2] U. Schwabe and D. Paffrath, Eds., Arzneiverordnungs-Report 2008, Springer, Heidelberg, Germany, 2008.

[3] C. Scheidt-Nave and M. Dören, "Editorial," in Hormontherapie bei (post-) menopausalen Frauen in Deutschland 2007. Studienergebnisse zu Nutzen, Risiken und Versorgungsrealität, Robert Koch-Institut, Ed., vol. 2008, pp. 5-12, Berlin, Germany.

[4] G. L. Anderson, M. Limacher, A. R. Assaf et al., "Effects of conjugated equine estrogen in postmenopausal women with hysterectomy: the Women's Health Initiative randomized controlled trial," The Journal of the American Medical Association, vol. 291, no. 14, pp. 1701-1712, 2004.

[5] J. E. Rossouw, G. L. Anderson, R. L. Prentice et al., "Risks and benefits of estrogen plus progestin in healthy postmenopausal women: principal results from the Women's Health Initiative randomized controlled trial," Journal of the American Medical Association, vol. 288, no. 3, pp. 321-333, 2002.

[6] G. P. Cumming, J. Herald, R. Moncur, H. Currie, and A. J. Lee, "Women's attitudes to hormone replacement therapy, alternative therapy and sexual health: a web-based survey," Menopause International, vol. 13, no. 2, pp. 79-83, 2007.

[7] A.-M. Beer and B. Nobis, "Gynäkologische Erkrankungen und Geburtshilfe," in Leitfaden Naturheilverfahren für die ärztliche Praxis, A.-M. Beer and M. Adler, Eds., pp. 521-556, Elsevier, Urban \& Fischer, München, Germany, 2011.

[8] EMA European Medicine Agency. Committee on Herbal Medicinal Products (HMPC). Community herbal mono-graph on Cimicifuga racemosa (L.) Nutt., rhizome. EMA/HMPC/ 600717/2007 Corr., 2011.

[9] ESCOP Monographs. CIMICIFUGAE RHIZOMA-Black Cohosh. European Scientific Cooperative on Phytotherapy, Exeter, UK, 2011, http://www.escop.com/.

[10] E. J. Kennelly, S. Baggett, P. Nuntanakorn et al., "Analysis of thirteen populations of black cohosh for formononetin," Phytomedicine, vol. 9, no. 5, pp. 461-467, 2002.

[11] B. Avula, Y. H. Wang, T. J. Smillie, and I. A. Khan, "Quantitative determination of triterpenoids and formononetin in rhizomes of black cohosh (Actaea racemosa) and dietary supplements by using UPLC-UV/ELS detection and identification by UPLCMS," Planta Medica, vol. 75, no. 4, pp. 381-386, 2009.

[12] M. J. Leach and V. Moore, "Black cohosh, (Cimicifuga spp.) for menopausal symptoms," Cochrane Database of Systematic Reviews, vol. 9, Article ID CD007244, 2012.

[13] C. Palacio, G. Masri, and A. D. Mooradian, "Black cohosh for the management of menopausal symptoms: a systematic review of clinical trials," Drugs and Aging, vol. 26, no. 1, pp. 23-36, 2009.

[14] F. Borrelli and E. Ernst, "Black cohosh (Cimicifuga racemosa) for menopausal symptoms: a systematic review of its efficacy," Pharmacological Research, vol. 58, no. 1, pp. 8-14, 2008.

[15] A.-M. Beer, "Herbal medicines used in kidney diseases in Europe," Iranian Journal of Kidney Diseases, vol. 5, no. 2, pp. 8285, 2011.

[16] F. Gaedcke and A.-M. Beer, "Pflanzliche Arzneimittel versus pflanzliche Nahrungsergänzungsmittel. Der Unterschied liegt in der Qualität," MMW: Fortschritte der Medizin, vol. 152, no. 16, pp. 36-38, 2010.

[17] Oxford Centre for Evidence-based Medicine Levels of Evidence (March 2009), http://www.cebm.net/index.aspx?o=4590.

[18] R. Osmers, M. Friede, E. Liske, J. Schnitker, J. Freudenstein, and H.-H. Henneicke-von Zepelin, "Efficacy and safety of isopropanolic black cohosh extract for climacteric symptoms," Obstetrics and Gynecology, vol. 105, pp. 1074-1083, 2005.

[19] E. Liske, W. Hänggi, H.-H. Henneicke-von Zepelin et al., "Physiological investigation of a unique extract of black cohosh (Cimicifugae racemosae rhizoma): a 6-month clinical study demonstrates no systemic estrogenic effect," Journal of Women's Health and Gender-Based Medicine, vol. 11, no. 2, pp. 163-174, 2002.

[20] W. Bai, H.-H. Henneicke-von Zepelin, S. Wang et al., "Efficacy and tolerability of a medicinal product containing an 
isopropanolic black cohosh extract in Chinese women with menopausal symptoms: a randomized, double blind, parallelcontrolled study versus tibolone," Maturitas, vol. 58, no. 1, pp. 31-41, 2007.

[21] R. E. Nappi, B. Malavasi, B. Brundu, and F. Facchinetti, "Efficacy of Cimicifuga racemosa on climacteric complaints: a randomized study versus low-dose transdermal estradiol," Gynecological Endocrinology, vol. 20, no. 1, pp. 30-35, 2005.

[22] G. Vermes, F. Banhidy, and N. Acs, "The effects of Remifemin on subjective symptoms of menopause," Advances in Therapy, vol. 22, no. 2, pp. 148-154, 2005.

[23] M. Schmidt, W. Polasek, and R. Käufeler, "Wirksamkeit und Sicherheit von Traubensilberkerze (Cimicifuga racemosa, Cimifemin) bei Menopausebeschwerden: Therapiebeobachtung unter Praxisbedingungen," Journal für Menopause, vol. 12, no. 1, pp. 30-34, 2005.

[24] M. D. Julia Molla, Y. Garcia-Sanchez, A. R. Sarrio, and F. R. Perez-Lopez, "Cimicifuga racemosa treatment and health related quality of life in post-menopausal Spanish women," Gynecological Endocrinology, vol. 25, no. 1, pp. 21-26, 2009.

[25] V. Briese, U. Stammwitz, M. Friede, and H. H. Henneickevon Zepelin, "Black cohosh with or without St. John's wort for symptom-specific climacteric treatment-results of a largescale, controlled, observational study," Maturitas, vol. 57, no. 4, pp. 405-414, 2007.

[26] R. Uebelhack, J. U. Blohmer, H. J. Graubaum, R. Busch, J. Gruenwald, and K. D. Wernecke, "Black cohosh and St. John's wort for climacteric complaints: a randomized trial," Obstetrics and Gynecology, vol. 107, no. 2, pp. 247-255, 2006.

[27] D. J. Chung, H. Y. Kim, K. H. Park et al., "Black cohosh and St. John's wort (GYNO-Plus) for climacteric symptoms," Yonsei Medical Journal, vol. 48, no. 2, pp. 289-294, 2007.

[28] W. Wuttke, D. Seidlová-Wuttke, and C. Gorkow, "The Cimicifuga preparation BNO 1055 vs. conjugated estrogens in a double-blind placebo-controlled study: effects on menopause symptoms and bone markers," Maturitas, vol. 44, supplement 1, pp. S67-S77, 2003.

[29] W. Wuttke, K. Rauš, and C. Gorkow, "Efficacy and tolerability of the Black cohosh (Actaea racemosa) ethanolic extract BNO 1055 on climacteric complaints: a double-blind, placebo- and conjugated estrogens-controlled study," Maturitas, vol. 55, no. 1, pp. S83-S91, 2006.

[30] K. Rauš, C. Brucker, C. Gorkow, and W. Wuttke, "Firsttime proof of endometrial safety of the special black cohosh extract (Actaea or Cimicifuga racemosa extract) CR BNO 1055," Menopause, vol. 13, no. 4, pp. 678-691, 2006.

[31] W. D. Kaiser, R. Martin, R. Schellenberg, E. Schrader, and R. Saller, "Cimicifuga-racemosa-Extrakt Ze 450 bei Wechseljahrbeschwerden," Ars Medici, vol. 17, pp. 771-774, 2008.

[32] S. Frei-Kleiner, W. Schaffner, V. W. Rahlfs, C. Bodmer, and M. Birkhäuser, "Cimicifuga racemosa dried ethanolic extract in menopausal disorders: a double-blind placebo-controlled clinical trial," Maturitas, vol. 51, no. 4, pp. 397-404, 2005.

[33] M. Oktem, D. Eroglu, H. B. Karahan, N. Taskintuna, E. Kuscu, and H. B. Zeyneloglu, "Black cohosh and fluoxetine in the treatment of postmenopausal symptoms: a prospective, randomized trial," Advances in Therapy, vol. 24, no. 2, pp. 448-461, 2007.

[34] R. L. Ruhlen, J. Haubner, J. K. Tracy et al., "Black cohosh does not exert an estrogenic effect on the breast," Nutrition and Cancer, vol. 59, no. 2, pp. 269-277, 2007.

[35] K. M. Newton, S. D. Reed, A. Z. LaCroix, L. C. Grothaus, K. Ehrlich, and J. Guiltinan, "Treatment of vasomotor symptoms of menopause with black cohosh, multibotanicals, soy, hormone therapy, or placebo: a randomized trial," Annals of Internal Medicine, vol. 145, no. 12, pp. 869-879, 2006.

[36] S. E. Geller, L. P. Shulman, R. B. van Breemen et al., "Safety and efficacy of black cohosh and red clover for the management of vasomotor symptoms: a randomized controlled trial," Menopause, vol. 16, no. 6, pp. 1156-1166, 2009.

[37] B. Naser, J. Schnitker, M. J. Minkin, S. Garcia de Arriba, K. U. Nolte, and R. Osmers, "Suspected black cohosh hepatotoxicity: no evidence by meta-analysis of randomized controlled clinical trials for isopropanolic black cohosh extract," Menopause, vol. 18, no. 4, pp. 366-375, 2011.

[38] E. Lundström, A. L. Hirschberg, and G. Söderqvist, "Digitized assessment of mammographic breast density. Effects of continuous combined hormone therapy, tibolone and black cohosh compared to placebo," Maturitas, vol. 70, no. 4, pp. 361-364, 2011.

[39] J. S. Jacobson, A. B. Troxel, J. Evans et al., "Randomized trial of black cohosh for the treatment of hot flashes among women with a history of breast cancer," Journal of Clinical Oncology, vol. 19, no. 10, pp. 2739-2745, 2001.

[40] M. A. García-Pérez, B. Pineda, C. Hermenegildo, J. J. Tarín, and A. Cano, "Isopropanolic Cimicifuga racemosa is favorable on bone markers but neutral on an osteoblastic cell line," Fertility and Sterility, vol. 91, no. 4, supplement, pp. 1347-1350, 2009.

[41] M. Rostock, J. Fischer, A. Mumm, U. Stammwitz, R. Saller, and H. H. Bartsch, "Black cohosh (Cimicifuga racemosa) in tamoxifen-treated breast cancer patients with climacteric complaints-a prospective observational study," Gynecological Endocrinology, vol. 27, no. 10, pp. 844-848, 2011.

[42] N. E. Reame, J. L. Lukacs, V. Padmanabhan, A. D. Eyvazzadeh, Y. R. Smith, and J. K. Zubieta, "Black cohosh has central opioid activity in postmenopausal women: evidence from naloxone blockade and positron emission tomography neuroimaging," Menopause, vol. 15, no. 5, pp. 832-840, 2008.

[43] A. Lindén-Hirschberg, M. Edlund, G. Svane, E. Azavedo, L. Skoog, and B. von Schoultz, "An isopropanolic extract of black cohosh does not increase mammographic breast density or breast cell proliferation in postmenopausal women," Menopause, vol. 14, no. 1, pp. 89-96, 2007.

[44] B. A. Pockaj, C. L. Loprinzi, J. A. Sloan et al., "Pilot evaluation of black cohosh for the treatment of hot flashes in women," Cancer Investigation, vol. 22, no. 4, pp. 515-521, 2004.

[45] N. Obi, J. Chang-Claude, J. Berger et al., "The use of herbal preparations to alleviate climacteric disorders and risk of postmenopausal breast cancer in a German case-control study," Cancer Epidemiology Biomarkers and Prevention, vol. 18, no. 8, pp. 2207-2213, 2009.

[46] T. R. Rebbeck, A. B. Troxel, S. Norman et al., "A retrospective case-control study of the use of hormone-related supplements and association with breast cancer," International Journal of Cancer, vol. 120, no. 7, pp. 1523-1528, 2007.

[47] H. H. Henneicke-von Zepelin, H. Meden, K. Kostev, D. Schröder-Bernhardi, U. Stammwitz, and H. Becher, "Isopropanolic black cohosh extract and recurrence-free survival after breast cancer," International Journal of Clinical Pharmacology and Therapeutics, vol. 45, no. 3, pp. 143-154, 2007.

[48] W. Wuttke, C. Gorkow, and D. Seidlová-Wuttke, "Effects of black cohosh (Cimicifuga racemosa) on bone turnover, vaginal mucosa, and various blood parameters in postmenopausal women: a double-blind, placebo-controlled, and conjugated 
estrogens-controlled study," Menopause, vol. 13, no. 2, pp. 185196, 2006.

[49] G. Hernández Muñoz and S. Pluchino, "Cimicifuga racemosa for the treatment of hot flushes in women surviving breast cancer," Maturitas, vol. 44, supplement 1, pp. S59-S65, 2003.

[50] A. Nasr and H. Nafeh, "Influence of black cohosh (Cimicifuga racemosa) use by postmenopausal women on total hepatic perfusion and liver functions," Fertility and Sterility, vol. 92, no. 5, pp. 1780-1782, 2009.

[51] L. Spangler, K. M. Newton, L. C. Grothaus, S. D. Reed, K. Ehrlich, and A. Z. LaCroix, "The effects of black cohosh therapies on lipids, fibrinogen, glucose and insulin," Maturitas, vol. 57, no. 2, pp. 195-204, 2007.

[52] S. D. Reed, K. M. Newton, A. Z. LaCroix, L. C. Grothaus, V. S. Grieco, and K. Ehrlich, "Vaginal, endometrial, and reproductive hormone findings: randomized, placebo-controlled trial of black cohosh, multibotanical herbs, and dietary soy for vasomotor symptoms: the Herbal Alternatives for Menopause (HALT) Study," Menopause, vol. 15, no. 1, pp. 51-58, 2008.

[53] B. M. Johnson and R. B. van Breemen, "In vitro formation of quinoid metabolites of the dietary supplement Cimicifuga racemosa (black cohosh)," Chemical Research in Toxicology, vol. 16, no. 7, pp. 838-846, 2003.

[54] R. B. van Breemen, W. Liang, S. Banuvar et al., "Pharmacokinetics of 23-epi-26-deoxyactein in women after oral administration of a standardized extract of black cohosh," Clinical Pharmacology and Therapeutics, vol. 87, no. 2, pp. 219-225, 2010.

[55] B. J. Gurley, S. F. Gardner, M. A. Hubbard et al., "In vivo effects of goldenseal, kava kava, black cohosh, and valerian on human cytochrome P450 1A2, 2D6, 2E1, and 3A4/5 phenotypes," Clinical Pharmacology and Therapeutics, vol. 77, no. 5, pp. 415426, 2005.

[56] B. J. Gurley, G. W. Barone, D. K. Williams et al., "Effect of milk thistle (Silybum marianum) and black cohosh (Cimicifuga racemosa) supplementation on digoxin pharmacokinetics in humans," Drug Metabolism and Disposition, vol. 34, no. 1, pp. 69-74, 2006.

[57] J. D. Amsterdam, Y. Yao, J. J. Mao, I. Soeller, K. Rockwell, and J. Shults, "Randomized, double-blind, placebo-controlled trial of Cimicifuga racemosa (black cohosh) in women with anxiety disorder due to menopause," Journal of Clinical Psychopharmacology, vol. 29, no. 5, pp. 478-483, 2009.

[58] F. Firenzuoli, L. Gori, and P. Roberti di Sarsina, "Black cohosh hepatic safety: follow-up of 107 patients consuming a special Cimicifuga racemosa rhizome herbal extract and review of literature," Evidence-Based Complementary and Alternative Medicine, vol. 2011, Article ID 821392, 7 pages, 2011.

[59] T. M. Brasky, J. W. Lampe, J. D. Potter, R. E. Patterson, and E. White, "Specialty supplements and breast cancer risk in the VITamins and Lifestyle (VITAL) cohort," Cancer Epidemiology Biomarkers and Prevention, vol. 19, no. 7, pp. 1696-1708, 2010.

[60] A.-M. Beer, "Cimicifuga racemosa (Traubensilberkerze, Wanzenkraut)," in Naturheilverfahren und unkonventionelle medizinische Richtungen, M. Bühring and F. H. Kemper, Eds., 08.19, Springer Loseblatt Systeme, 1997.

[61] Commission E of the German Health Authority. Monograph Cimicifugae racemosae rhizoma. BAnz, 43, 1070, 1989.

[62] G. A. Hauser, "Häufigkeit klimakterischer Symptome-eine Literaturübersicht," in Menopause, Hormonsubstitution heute, C. Lauritzen, Ed., Band 5, pp. 18-21, Stabil Verlag GmbH, München, Germany, 1992.
[63] F. A. Leidenberger, Klinische Endokrinologie für Frauenärzte, 134, Springer, Berlin, Germany, 1998.

[64] B. Jiang, F. Kronenberg, P. Nuntanakorn, M.-H. Qiu, and E. J. Kennelly, "Evaluation of the botanical authenticity and phytochemical profile of black cohosh products by high-performance liquid chromatography with selected ion monitoring liquid chromatography-mass spectrometry," Journal of Agricultural and Food Chemistry, vol. 54, no. 9, pp. 3242-3253, 2006.

[65] European Medicine Agency. Committee on Herbal Medicinal Products (HMPC). Assessment of case reports connected to herbal medicinal products containing Cimicifugae racemosae rhizoma (Black cohosh, root). Doc Ref: EMEA/HMPC/ 269258/2006 Rev. 1., 2007.

[66] R. Teschke and A. Schwarzenboeck, "Suspected hepatotoxicity by Cimicifugae racemosae rhizoma (black cohosh, root): critical analysis and structured causality assessment," Phytomedicine, vol. 16, no. 1, pp. 72-84, 2009.

[67] G. B. Mahady, T. Low Dog, M. L. Barrett et al., "United States Pharmacopeia review of the black cohosh case reports of hepatotoxicity," Menopause, vol. 15, no. 4, part 1, pp. 628-638, 2008.

[68] R. Teschke, "Black cohosh and suspected hepatotoxicity: inconsistencies, confounding variables, and prospective use of a diagnostic causality algorithm. A critical review," Menopause, vol. 17, no. 2, pp. 426-440, 2010.

[69] R. Teschke, R. Bahre, A. Genthner, J. Fuchs, W. SchmidtTaenzer, and A. Wolff, "Suspected black cohosh hepatotoxicity-challenges and pitfalls of causality assessment," Maturitas, vol. 63, no. 4, pp. 302-314, 2009.

[70] R. Teschke, R. Bahre, J. Fuchs, and A. Wolff, "Black cohosh hepatotoxicity: quantitative causality evaluation in nine suspected cases," Menopause, vol. 16, no. 5, pp. 956-965, 2009.

[71] R. Teschke, A. Schwarzenboeck, W. Schmidt-Taenzer, A. Wolff, and K.-H. Hennermann, "Herb induced liver injury presumably caused by black cohosh: a survey of initially purported cases and herbal quality specifications," Annals of Hepatology, vol. 10, no. 3, pp. 249-259, 2011.

[72] R. Teschke, W. Schmidt-Taenzer, and A. Wolff, "Spontaneous reports of assumed herbal hepatotoxicity by black cohosh: is the liver-unspecific Naranjo scale precise enough to ascertain causality?" Pharmacoepidemiology and Drug Safety, vol. 20, no. 6, pp. 567-582, 2011.

[73] R. Teschke and J. Schulze, "Suspected herbal hepatotoxicity: requirements for appropriate causality assessment by the US Pharmacopeia," Drug Safety, vol. 35, no. 12, pp. 1091-1097, 2012. 


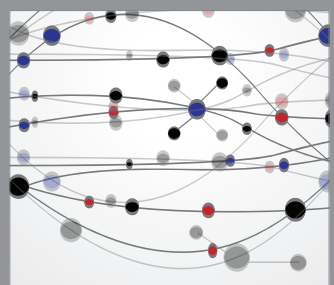

The Scientific World Journal
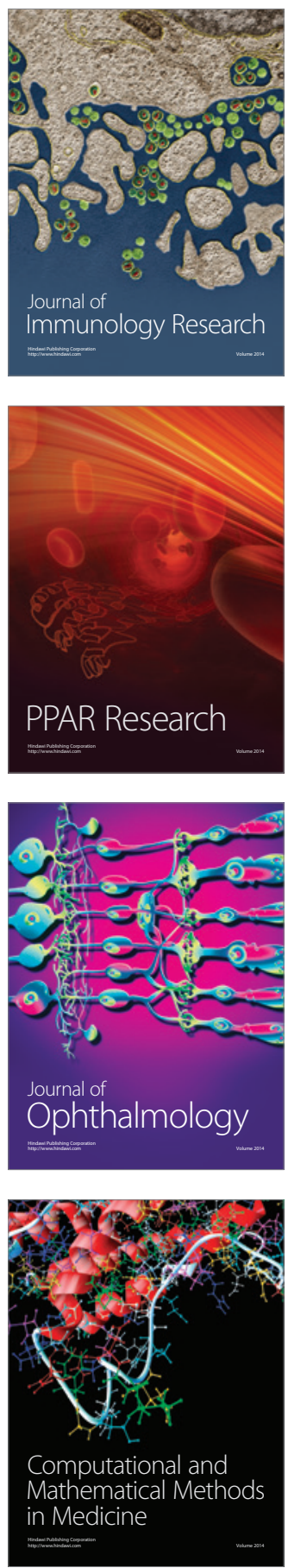

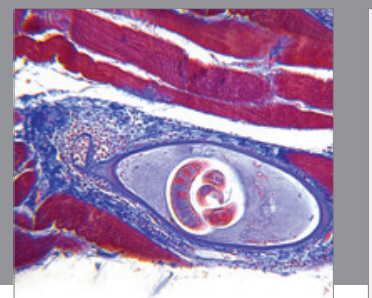

Gastroenterology

Research and Practice
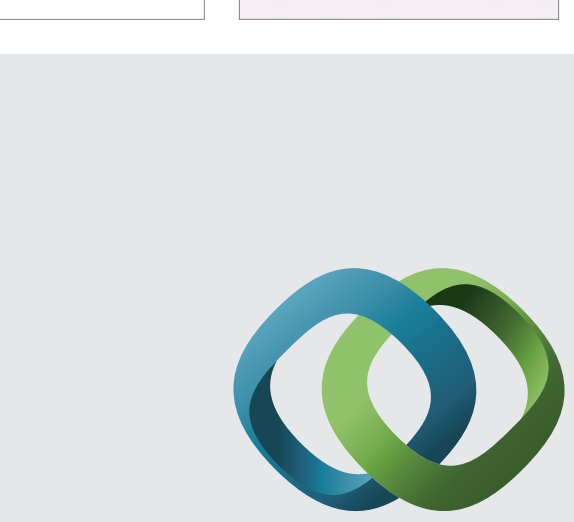

\section{Hindawi}

Submit your manuscripts at

http://www.hindawi.com
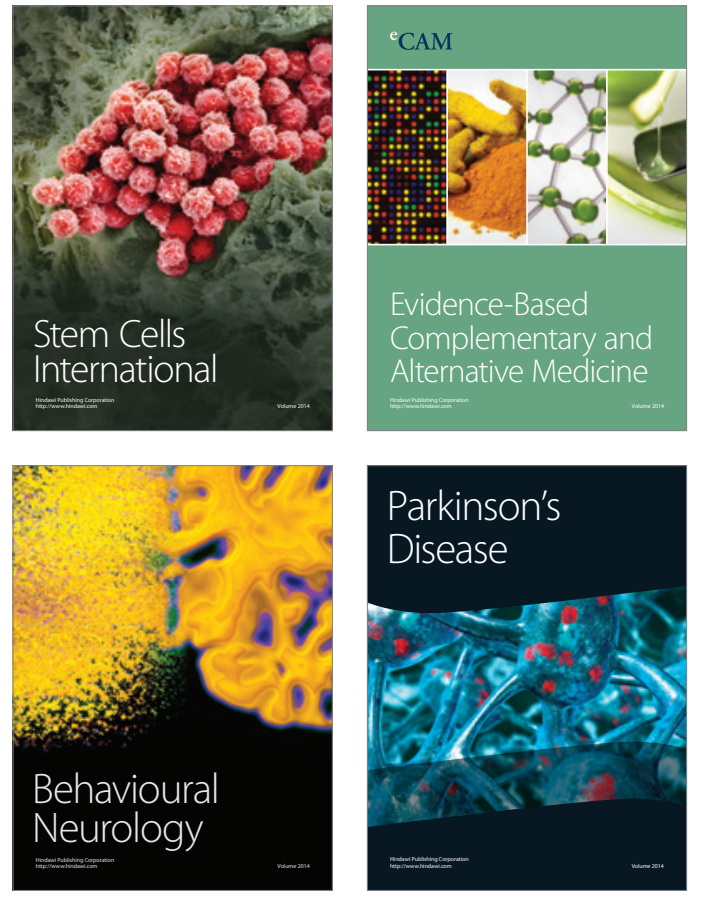
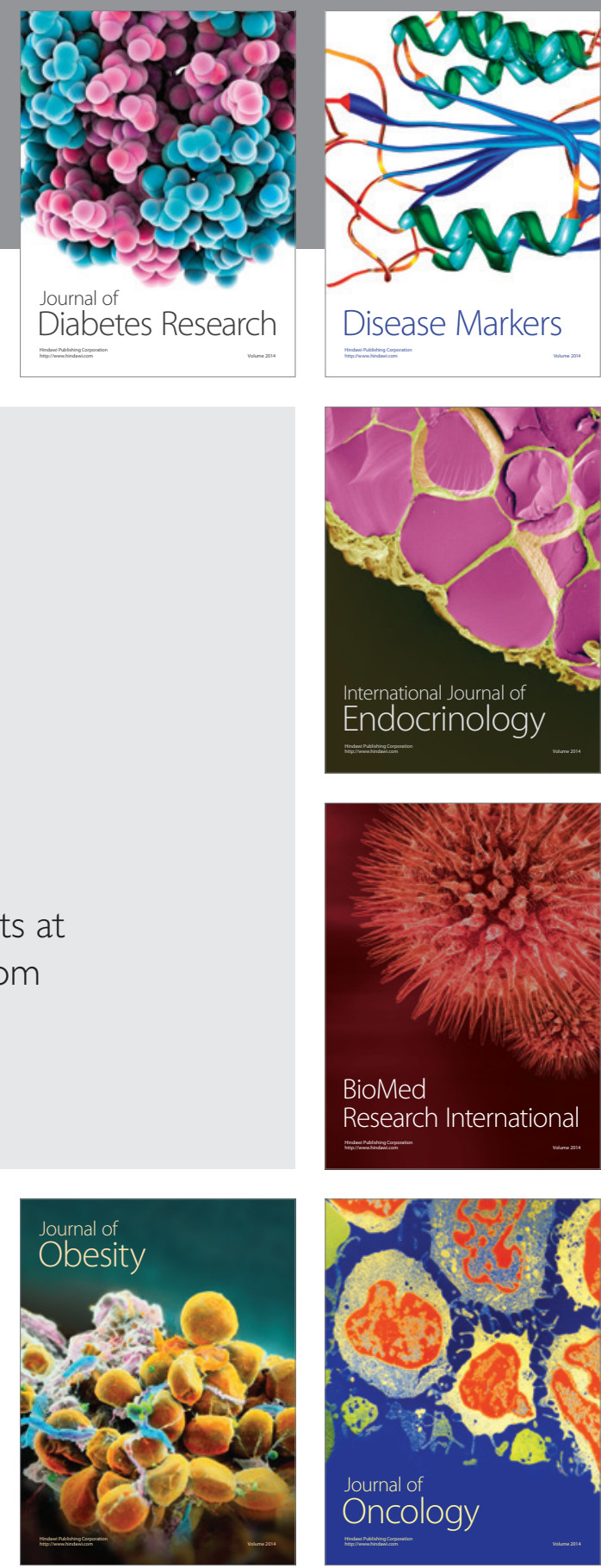

Disease Markers
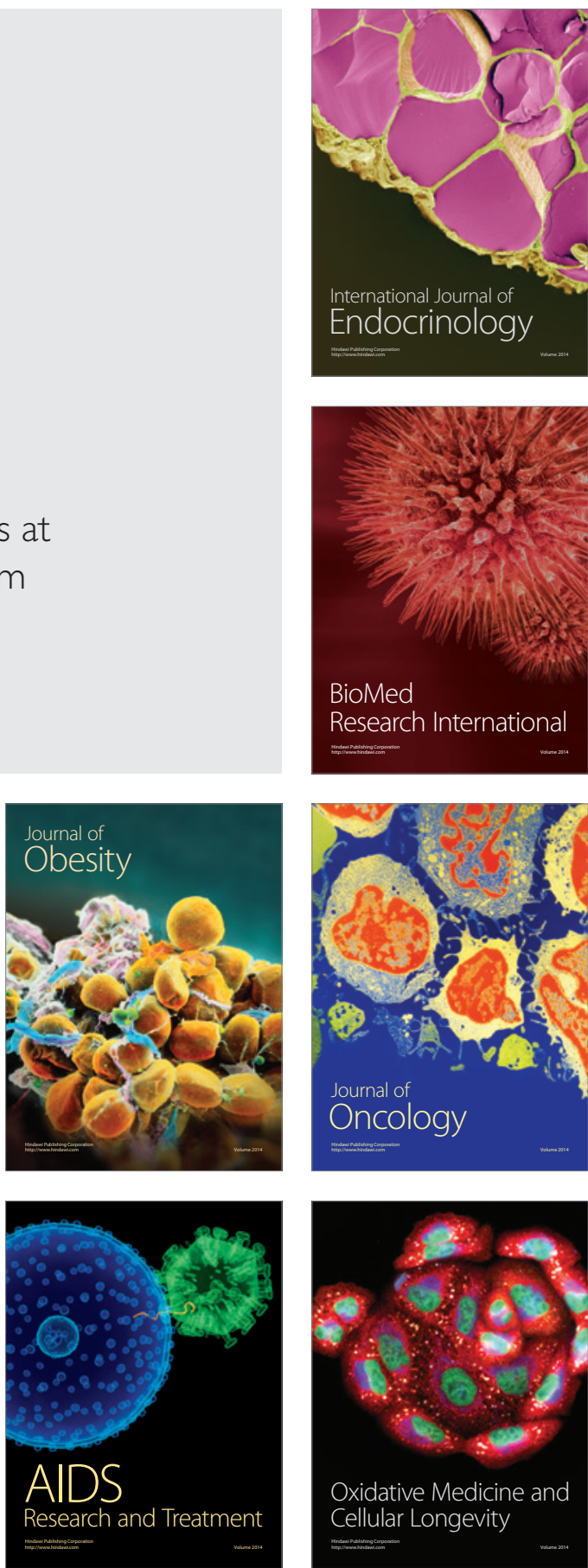